Portland State University

PDXScholar

Summer 8-6-2014

\title{
It's Complicated: The Role of Facebook in Romantic Relationships Concerning Relational Certainty, Attachment, and Self-Esteem
}

Jenna Rae Tucker

Portland State University

Follow this and additional works at: https://pdxscholar.library.pdx.edu/open_access_etds

Part of the Social Media Commons, and the Social Psychology Commons Let us know how access to this document benefits you.

\section{Recommended Citation}

Tucker, Jenna Rae, "It's Complicated: The Role of Facebook in Romantic Relationships Concerning Relational Certainty, Attachment, and Self-Esteem" (2014). Dissertations and Theses. Paper 1983. https://doi.org/10.15760/etd.1982

This Thesis is brought to you for free and open access. It has been accepted for inclusion in Dissertations and Theses by an authorized administrator of PDXScholar. Please contact us if we can make this document more accessible: pdxscholar@pdx.edu. 
It's Complicated: The Role of Facebook in Romantic Relationships Concerning Relational Certainty, Attachment, and Self Esteem

\author{
by \\ Jenna Rae Tucker
}

A thesis submitted in partial fulfillment of the requirements for the degree of

\author{
Master of Science \\ in \\ Communication
}

\author{
Thesis Committee: \\ Lauren Frank, Chair \\ Lee Shaker \\ Kristine Munholland
}

Portland State University 2014 
(C) 2014 Jenna Rae Tucker 


\begin{abstract}
Facebook is among the top used websites in the world, and research has shown that Facebook use is related to individual personality characteristics such as well-being and self-esteem. This study builds on previous research, expanding to investigate attachmentrelated anxiety and avoidance and relational certainty. The current study examined relationships between Facebook use (both general and for surveillance) and relational certainty, attachment-related anxiety and avoidance, and self-esteem in undergraduate students $(\mathrm{N}=261)$. Online methods were used for data collection, and individuals with their relationship displayed on Facebook reported more relational certainty, however the more time they spent on the site the less certain they were with their relationship. Individuals with high attachment-related anxiety were more likely to use Facebook for surveillance, and both attachment anxiety and Facebook use for surveillance were linked to lower self-esteem. These findings indicate that individuals with their relationship status displayed on Facebook have more relational certainty and exhibit less attachment anxiety and avoidance. Individuals with high attachment anxiety use Facebook for surveillance. These results add to the expanding literature on Facebook and social networking sites, showing that different people use Facebook in varying ways. As social networking continues to be a staple in the lives of nearly one billion users, it is important to keep researching how it people use it and what the potential implications are of this use.
\end{abstract}




\section{Dedication}

This work, a culmination of all of my years of schooling and hard work, is in honor of my mother. Without her it would have been nearly impossible to reach this point for many different reasons. 


\section{Acknowledgments}

This thesis and the adventure through grad school in general, would not have been possible without a support system. I would like to thank some of the people who helped make up that system.

First, a giant thank you to Dr. Lauren Frank who patiently answered all of my questions and assured me that my freak outs were unjustified. She offered guidance, advice, and words of encouragement for the entire process of writing this thesis. I would also like to thank my committee members Dr. Lee Shaker and Dr. Kristine Munholland, whose expertise and insight added so much to my own writing and helped tie everything together.

Thank you to my mom and my stepdad who helped me financially and never had a doubt that I would finish and finish on time. Archana and Jesse, thank you for letting me constantly talk at you about the work I needed to do and letting me organize ideas out loud even though you had no idea what I was talking about. Tim, you are my best friend.

A giant thank you to Sarah Martin, honestly I could not have completed this on time without you being on top of every deadline and pushing me to stay on track. And thank you to the remainder of my cohort, we lost a few in the beginning, but we stuck it out and made it through the process. We will master life! 


\section{Table of Contents}

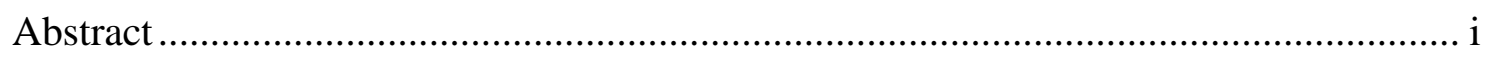

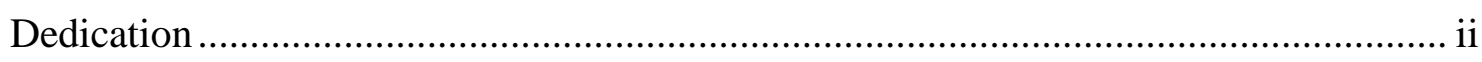

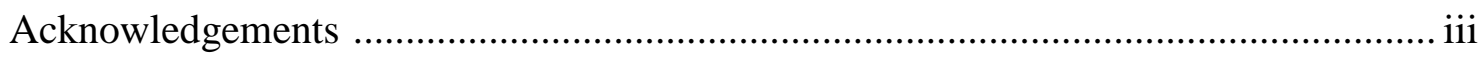

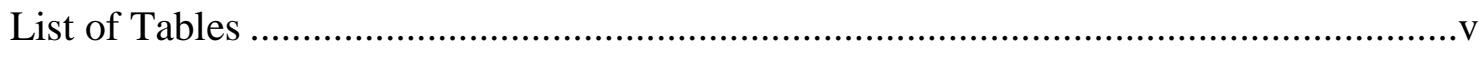

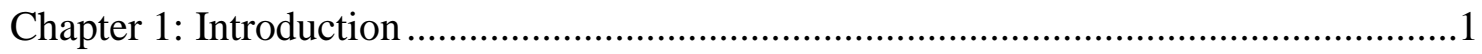

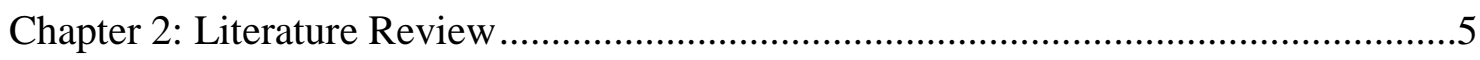

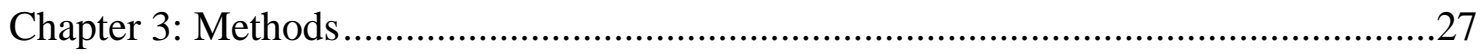

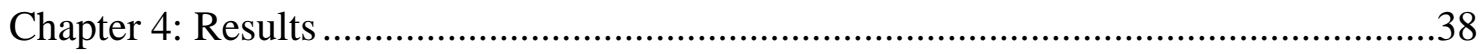

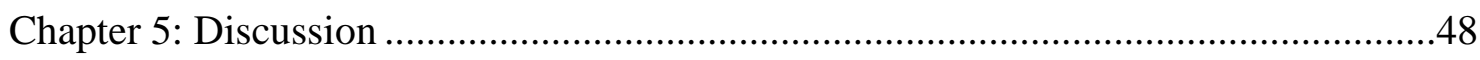

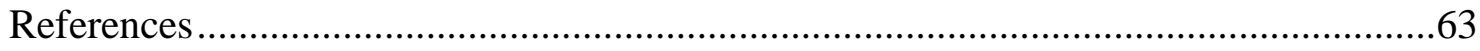

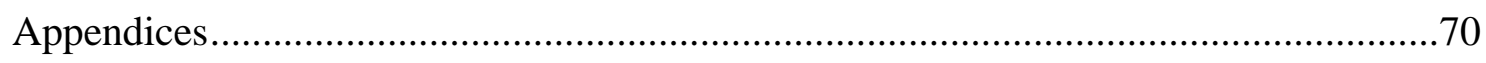

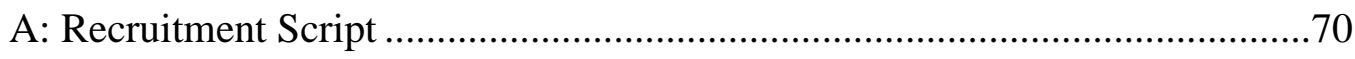

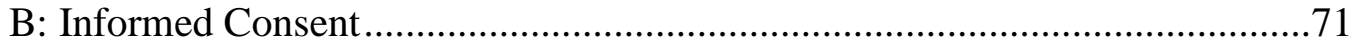

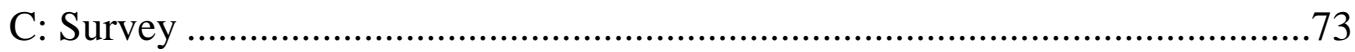




\section{List of Tables}

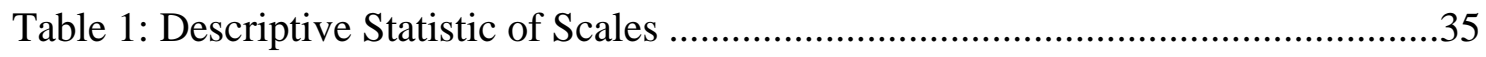

Table 2: Self-Esteem by Attachment Anxiety and Facebook Surveillance ...................44

Table 3: Self-Esteem by Attachment Avoidance and Facebook Surveillance ...............45 


\section{Chapter 1: Introduction}

Reducing uncertainty is a key aspect in the formation of relationships, romantic or otherwise. Relational uncertainty is characterized as the lack of confidence people have in their perceptions of their involvement in interpersonal connections (Knobloch \& Solomon, 2009). According to Berger and Calabrese's (1975) uncertainty reduction theory (URT), people will question others in an initial meeting in order to learn about the individual as well as to reduce unpredictability. Uncertainty reduction theory essentially states that an individual will be less satisfied with a relationship if they are uncertain about that relationship (Afifi \& Burgoon, 1998). If individuals are interested in continuing to build a relationship after the initial interaction, they then follow steps and strategies to continue reducing uncertainty within that relationship.

In the past, people typically had to participate in face-to-face communication when using uncertainty reducing strategies. However, this began to change when new technologies were introduced to the public. People were soon able to communicate with each other via e-mail and instant messaging. Eventually, social networking sites were developed, and as of 2014 they are a mainstay in a large number of people's lives, with Facebook alone having over one billion registered users (Facebook Key Facts, 2013). In April of 2014, Facebook was the second most used website of any kind globally as well as in the United States (Alexa, 2014). The site provides a wealth of user-generated information via profile pages, which are often available for anyone to view, depending on security settings. Profiles can typically contain as much personal information as desired which makes Facebook a great candidate to reduce potential uncertainty for burgeoning relationships, especially because it is not always necessary to communicate in order to 
gain the knowledge. Although reducing uncertainty passively can be positive, it might also impact how users communicate in relationships. If individuals can obtain information without speaking to one another, they might reduce communication, which could have a negative impact on their relationship.

Facebook profiles can contain a wealth of information about users, so it is a great candidate for interpersonal electronic surveillance (IES), or strategies employed online to monitor someone's behavior (Tokanuga, 2011). Although IES could potentially reduce uncertainty in a relationship and ultimately increase intimacy (Berger \& Calabrese, 1975), it might also have the opposite effect or no effect at all on relationships. With little research monitoring how Facebook impacts communication within romantic relationships, it is hard to draw a conclusion.

As humans we often pride ourselves on being unique, so it stands to reason that using Facebook as a way to monitor a significant other's activity and reduce uncertainty might have different impacts for people depending on the internal workings of their relationships. Attachment styles are developed from early interactions with caregivers and may influence how individuals behave in relationships, aiding to shape how people react to events that spawn uncertainty. Someone with high attachment avoidance might elude communication of certain events all together, even on Facebook, while someone with high attachment-related anxiety might seek comfort on Facebook; keeping tabs on a partner might ease worries or create new ones. Little research exists on Facebook use and attachment-related anxiety and avoidance as a whole. It is possible that individuals with differing attachment behaviors use Facebook in different ways, especially for certain activities, like surveillance for uncertainty reduction. While surveillance and attachment 
have not frequently been studied in relation to Facebook use, self-esteem has been

researched in multiple studies and has been found to have contradicting relationships with Facebook use. Positive correlations have been found (Ellison, Steinfield, \& Lampe, 2007) as well as negative correlations (Neira \& Barber, 2014). Typically, individuals with higher self-esteem are more satisfied in their relationships (Dion \& Dion, 1975), so it is possible that being more satisfied in a relationship would lead to lower relational uncertainty. But when Facebook enters the scenario, the relationship becomes muddied. Much of the research pertaining to Facebook is solely on individual use; however, few studies have looked at users who categorize themselves through a relationship status. Facebook use might have a very different relationship with self-esteem for someone who has their relationship displayed on the site versus someone who does not.

Research is also sparse concerning using Facebook for specific activities, such as internet electronic surveillance (IES). Self-esteem and Facebook use might have a different relationship when Facebook is being used for surveillance activities rather than just being measured for time spent on the site. Although Facebook can be used to monitor romantic relationships through activities like IES, little research exists examining the potential effects of the site on these relationships. The overall aim of this study was to showcase the differences in Facebook use for people with varying personalities. More specifically, this study aimed to determine if relationships existed between Facebook use in general, as well as use for surveillance, and relational uncertainty, attachment-related anxiety and avoidance, and self-esteem. Previous research has only concerned itself with one of these characteristics: self-esteem. In order to show support for the ideas presented in this study, a review of the important literature is necessary. Included in this review 
will be hypotheses and research questions (Chapter 2), which will be followed by the methodology used to test these questions (Chapter 3). Next will be the results from the data collection (Chapter 4), followed by a discussion of these findings, and lastly a summary of the overall study (Chapter 5).

This study shows the importance of researching social networking sites, specifically Facebook, and their potential impacts on romantic relationships and other individual characteristics of users. While displaying a relationship on Facebook was linked with higher relational certainty and lower attachment-related anxiety and avoidance for individuals in current romantic relationships, Facebook use for surveillance was associated with lower self-esteem and higher attachment-related anxiety. Additionally, general time spent on Facebook was also linked to lower relational certainty for individuals with their relationship status displayed. These findings support the idea that Facebook is used differently amongst individuals in romantic relationships. These ideas are further discussed in the following chapters. 


\section{Chapter 2: Literature Review}

Over the past decade, social networking sites have become some of the most widely used websites on the internet (Alexa, 2014). Facebook alone has over one billion registered users (Facebook Key Facts, 2013). In fact, residents of the United States spend more time on Facebook than any other website (Nielsen, 2011), and college students average one to two hours each day on the site (Kalpidou, Costin, \& Morris, 2011). The main motivation for Facebook use is to keep in touch with friends with whom relationships have already been established offline (Joinson, 2008). However, the second most common motivation is social surveillance (Joinson, 2008). According to Stern and Taylor (2007), one of the most frequent reasons for students to use Facebook is to check up on their significant other as well as to find out what their friends are doing on the internet. In fact, 60 percent of college students have admitted to using Facebook as a way to survey partners and friends (Stern \& Taylor, 2007).

\section{Facebook: A Brief History}

Ellison and Boyd (2008) define social networking sites as web-based services that allow individuals to make a profile page that can be shared with a select group of people whose profiles can also be browsed by the individual (p. 211). Although Facebook has continuously added new elements over the years, such as online chat and games, many of the original elements still remain parts of the site. Profile pages still contain "About Me" sections where the owner of the profile fills in information about themselves such as their religious or political affiliation, workplace, and school information. Users can also share their favorite music, movies, quotes, books, television shows, and other websites or pages that they like. Users are able to upload their own pictures as well as tag friends in these 
pictures. When users tag someone, essentially they attach a link to that user's page, the picture then appears on that friend's timeline, and their name appears on the tagged image when the cursor rolls over it. Facebook users can comment on friends' walls and receive comments from friends as well. Depending on the privacy settings users choose for their profiles, all of this information is available for anyone to view.

As Facebook has grown over the years, it has adopted new privacy issues and given users more options for security. Facebook users can customize their settings to choose who sees their content. Users have the option to share statuses or posts with everyone who has a Facebook account, current Facebook friends plus their friends, or current Facebook friends only. The option also exists not to share status updates with specific friends (Facebook, n.d.). Not sharing statuses with certain people means that they cannot see updates, nor will the updates appear in that person's newsfeed, or stream of updates by friends (Facebook, n.d.). Facebook users also have the option to block certain people; this means that the user who is blocked cannot access the blocker's Facebook page at all; essentially the user ceases to exist (Facebook, n.d.). Users similarly have the ability to choose who can contact them via personal messages and friend requests or look up their profile via their e-mail address. Another option exists where users must approve any tags or posts before they can be posted to their timeline (Facebook, n.d.).

A primary piece of personal information that Facebook allows users to display on their profile is current relationship status. If users choose to display their relationship status, they have the ability to choose from a status of single, widowed, it's complicated, in a relationship, divorced, in a civil union, in a domestic partnership, or married. Users can display their status singularly (ex: John Doe is in a relationship) or ask to have their 
profile connected to another user's, such as “Jane Doe is in a relationship with John

Doe." Jane Doe's profile will then be linked to John's if he confirms the relationship once a request is sent to him, and it will be listed in the "About Me" section of both users. John's name then becomes a hyperlink that clicks through to his profile from Jane's. Because many Facebook users display all of this personal information readily, Facebook makes it possible to learn a great deal about someone by simply surveying their profile; it is not necessary to actually interact with them to gain information (Fox, Warber, \& Makstaller, 2013).

\section{Uses and Gratifications}

Facebook and similar networking sites are used around the world by millions of people, but why are these sites so popular? According to the uses and gratifications theory, audiences actively seek out media in a goal-directed way that allows them to gratify a wide variety of needs (Katz, Blumler, \& Gurevitch, 1974). In other words, people have an important role in deciding how and why they use specific media. After a goal is determined, a person makes a decision based on previous use of media with the intent to satisfy a specific need or needs (Lim \& Ting, 2012). Media compete with each other to satisfy an audience member's needs; which can include such things as entertainment, information seeking, time killing, and more (Lim \& Ting, 2012). Rubin (1994) states that the overall goal of uses and gratifications theory is to explain what shapes a person's use of media and motivates them to engage in one medium over another to fulfill needs.

Where the internet is concerned, audiences might be motivated to use a specific internet site for information or content that is directly related to that site (Stafford \& 
Stafford, 1998). Social networking sites allow users to display information about themselves and in turn, find out information about other users. Raacke and Bonds-Raacke (2007) found that the main goals of surveyed college students for using social networking sites were to stay in touch with old friends and to stay in touch with current friends. Similar to Raacke and Bonds-Raackes' findings, Quan-Haase and Young (2010) also discovered that social connectivity was a main motivation for Facebook use.

Although social support and connectivity have been found to be the main reasons for using social networking sites such as Facebook, Stern and Taylor (2007) discovered that keeping tabs on current boyfriends or girlfriends was also listed as both a frequent and semi-frequent use among students with Facebook accounts. Using Facebook to check up on romantic partner's activities might be a way to reduce relational uncertainty. Displaying a relationship status on Facebook might be considered a way to label the commitment so that it is publicly seen. This is considered a "secret test" (Baxter \& Wilmont, 1984), or a method that people use to try to reduce uncertainty within a relationship (Baxter \& Wilmont, 1984). Another type of secret test people tend to employ is spying on their partner (Bell and Buerkel-Rothfuss, 1990). Because of the amount of personal information that is potentially available on Facebook, it could be considered a good venue for snooping on people, including romantic partners. A wealth of information can be obtained simply by viewing profile pages; actual dialogue does not need to occur.

\section{Relational Uncertainty}

Using social networking sites such as Facebook to discover information about people or monitor their activity might be considered a way of reducing uncertainty about the relationship with that person. Uncertainty reduction theory (URT) states that when 
people meet, they are initially faced with uncertainties about each other's behaviors, beliefs, values, etc. They then use questions and other strategies to reduce this uncertainty and to predict future behavior (Berger \& Calabrese, 1975). The initial interaction between strangers usually begins with the entry phase where information exchange is focused on basic details such as demographics, and the exchange is typically symmetrical among participants (Berger \& Calabrese, 1975). The next phase is the personal phase in which information about less socially desirable items is obtained. After the personal phase comes the exit phase, where participants of the conversation determine the future route of the relationship, including whether it continues further or if it is terminated (Berger \& Calabrese, 1975). The duration of each phase can vary, and sometimes a personal phase might not even be reached (Berger \& Calabrese, 1975). Because Facebook users can include demographic information on their profile page, it is possible that the entry phase could be completed on the networking site without actually having to communicate with another person. Once the demographic information is obtained, a user could reach out for more personal information about their target. In fact, because messaging can be used on Facebook, it is possible that all three stages could be achieved using only the site. Uncertainty reduction theory has expanded from just initial interactions of strangers and is also used to describe romantic relationships. Brashers (2001) stated that uncertainty exists in relationships when the details of certain events are ambiguous, problematic, unavailable, or even inconsistent. This ambiguity causes problems in predicting future behavior of romantic partners which can lead to insecurity in the relationship (Berger \& Bradac, 1982). Relational uncertainty is typically broken into three different areas which include self, partner, and relationship (Berger \& Bradach, 1982). Self-uncertainty is how 
people question their own involvement or participation in a relationship, whereas partner uncertainty includes doubts that a person has about their partner's involvement in the relationship (Knobloch \& Solomon, 2005). Relationship uncertainty includes questions about the norms of the relationship or the definition of the relationship, (Knobloch \& Solomon, 2005). Relationship uncertainty focuses on the couple as a unit (Theiss, 2009).

URT axioms. Uncertainty reduction theory, whether used to explain interactions between strangers or romantic partners, is centered on seven axioms (Berger \& Calabrese, 1975), four of which are particularly relevant for uncertainty reduction that could take place on social networking sites. One axiom states that an increase in verbal communication will result in a decrease in uncertainty (Berger \& Calabrese, 1975). As people ask questions of one another or seek information in other ways, they become more aware of a person's characteristics. This can be argued for Facebook as well. Users might not necessarily be communicating verbally, although they could via messaging or commenting which encourages a back and forth dialogue. However, they could also be seeking information through profile pages and getting answers to potential questions simply by observing the information already provided on that person's profile page. Antheunis, Schouten, Valkenburg, and Peter (2011) found that people using computer mediated communication (CMC) used more terms of affection than those in face-to-face interactions. Furthermore, question asking and disclosure proportions were higher for those using CMC versus face-to-face interactions. This also aligns with Berger's third axiom, which states that if someone is highly uncertain then he or she will seek information to reduce that uncertainty (Berger \& Calabrese, 1975). As mentioned previously, people use question asking and disclosure to reduce uncertainty through 
CMC. The first half of conversations tend to be reliant on question asking and lead to more statements of verbal affection in the second half of the conversation (Antheuis et al., 2013).

Another axiom states that as nonverbal expressiveness increases, uncertainty will decrease. Often, non-verbal cues cannot be registered through computer mediated communication which could mean that the verbal communication axiom is weighted more heavily to compensate for this. Emoticons can be used both in chat and in comments on Facebook, but little research exists measuring how effective they are in replacing traditional non-verbal cues. Byron and Baldridge (2007) found that smiley face emoticons tend to reduce uncertainty in e-mails by signaling positive tones; however, the same may or may not be true of similar emoticons used on Facebook.

An additional axiom posits that when people have similarities their uncertainty about one another is reduced (Berger \& Calabrese, 1975). People can use Facebook to determine if they have common interests with others by looking at their "About Me" section which often contains information about their interests. They can also use Facebook to eventually communicate with the person to get more in depth information. And lastly, axiom seven focuses on uncertainty and liking; if uncertainty levels are high then liking will be low (Berger \& Calabrese, 1975). Antheunis, Schouten, and Peter (2009) discovered that while this axiom is true for social networking sites, it is not necessarily how much information is discovered, but rather the attractiveness of that information that determines how much people like each other.

Uncertainty reduction strategies. In order to test the axioms that structure uncertainty reduction theory, techniques are used to gather information about another 
person to help make sense of their emotions and intentions and predict their attitudes and behaviors (Berger \& Calabrese, 1975). Gibbs, Ellison, and Lai (2011) state that communication is key in reducing relational uncertainty. Communication allows people to learn about each other and disclose information (Gibbs et al., 2011). They also state that uncertainty reduction strategies may be more difficult to participate in online because of the lack of nonverbal and traditional cues (Gibbs et al., 2011). However, uncertainty reduction strategies are still used via computer-mediated communication even though it might be considered more difficult (Byron \& Baldridge, 2007). Three types of uncertainty reduction strategies are typically used both online and offline and include passive, active, and interactive (Berger, 1979). Passive strategies are ones that include observing a person in an unobtrusive way (Berger, 1987). This can be in a situation where the person being observed is interacting with others or reacting to others (Antheunis et al., 2009). Information obtained passively might be altered if the subject being observed knew of the observation. Passive information is often gained through social interaction rather than solitary situations, such as observing a person at a party (Berger, 1987). While information about a target person can be gained from simply browsing a Facebook profile, users can also seek out conversations that have taken place on the target's Facebook wall or their friends' walls.

Active strategies are those in which a person attempts to gain information by asking others for information about the target person (Berger, 1987). People could use Facebook to find friends of a person and ask them questions to gain information about that person. Facebook also informs users of common friends so if two people share a friend, they could ask said friend for information. Interactive strategies are those that 
involve directly intermingling with a person to gain information about them (Berger, 1979). Questioning and self-disclosure are typically two ways to engage in interactive strategies in an offline environment (Berger, 1979). Facebook chat or messaging or commenting back and forth on each other's walls could be ways to directly interact with a person and gain information. Messaging would provide a more private interaction than wall comments, which would be seen by all Facebook friends.

Of the three strategies mentioned, passive strategies are the strategies employed most on social networking sites (Antheunis et al., 2009). Nearly 99\% of participants in a study admitted that they used one or more of the unobtrusive methods mentioned in the survey to gather information about people on social networking sites (Antheunis et al., 2009). Passive strategies included in the study were checking the person's blog, looking at their profile, looking at their pictures, and reading messages on their profile page (Antheunis et al., 2009). Although passive strategies were most often employed, interactive strategies were most successful in actually reducing uncertainty (Antheunis et al., 2009).

In a focus group about the role Facebook plays in relationship formation conducted by Fox, Warber, and Makstaller (2013) participants stated that becoming "Facebook official," or linking their Facebook profile to their partner's via their relationship status, is the new version of wearing someone's class ring; it sends a sign that this person is in a relationship and not available to date anyone else. Participants also generally agreed that because the relationship was able to be seen by the public on Facebook, the relationship needed to be stable before it was announced on the website (Fox et al, 2013). This is an example of a new norm being established; some people are 
now wary of the legitimacy of relationships if they are not displayed on Facebook (Fox et al., 2013).

Despite the fact that displaying a relationship status on Facebook seems like a straightforward behavior, often behaviors can be ambiguous even if they are explicitly stated, such as asking someone to get married (Planalp, 1987; Watzlawick et al., 1967) Displaying a relationship on Facebook might be a way to reduce ambiguity because it is available for not only the people in the relationship to see but also for all Facebook friends to see. It also might provide a sense of security and help reduce relational uncertainty since it is a visible commitment. This leads to the first hypothesis of this study:

H1: Participants who have their relationship status displayed on Facebook will be more certain about their relationships than those who do not display their relationship status.

As mentioned previously, Facebook users can also choose to link their page to their significant other's profile page. In doing this, each person's relationship status mentions the other's name. Instead of simply stating that "Jane Doe is in a relationship," the relationship status says that "Jane Doe is in a relationship with John Doe" (or married, engaged, etc.), and John's name is a hyperlink that, when clicked, takes a user to John's profile page. This blatant declaration of a relationship to all Facebook friends could decrease relational uncertainty. As Fox and colleagues (2013) discovered, "listing a relationship status on Facebook is perceived as both a social and interpersonal statement about the commitment two people share in a romantic relationship" (p. 12). This leads to the second hypothesis: 
H2: Individuals who have their relationship status displayed and linked to their partner's page will have less relational uncertainty than those who have their relationship status displayed but do not have their profiles linked.

\section{Interpersonal Electronic Surveillance}

One way to gain information using passive, active, and interactive strategies in an attempt to reduce relational uncertainty is through interpersonal electronic surveillance (IES), or strategies employed via communication devices to find out what people are doing on and offline (Tokunaga, 2011). These strategies are undertaken purposely with the goal of gaining knowledge about friends, romantic partners, co-workers, etc. (Tokunaga, 2011). IES is used on social networking sites because it is an easy way to gain information unobtrusively and there is easy access to a person's social network (Antheunis et al., 2009). Shoemaker (1996) states that people use surveillance as a way to observe what is going on around them. By surveying people, one can determine what sort of behaviors are going on around them that could potentially affect them in negative ways (Tokunaga, 2011). IES can occur online via bulletin boards, key stroke monitoring, personal webpages, blogs, and social networking sites including Facebook (Tokunaga, 2011).

Potentially, people could use Facebook as a way of monitoring what their friends or romantic partners are doing. For example, a woman could check her boyfriend's profile in an attempt to see if pictures have been posted from an event that occurred recently in order to determine if the details that he provided are indeed displayed in the photos. All users, depending on privacy settings, can also check their Facebook friends' status updates, comments from friends, and comments left on friends' walls, as well as 
other activity as it gets updated. This kind of surveillance allows for information to be acquired passively without actually asking for it and also to be acquired in real time or shortly thereafter.

Facebook offers four specific aspects that make it a good candidate for IES: accessibility, multimediation, recordability or archival, and geographical distance (Tokunaga, 2011). Accessibility refers to the degree to which information is easily gathered (Zhu \& He, 2002). Barring high privacy settings, as long as someone is friends with a person on Facebook they can see all of their personal information including pictures, videos, comments, status updates, and more. The fact that Facebook contains a wide variety of media such as those just listed is an example of multimediation (Walther, Gay, \& Hancock, 2004). Not only is all of this information easily accessible, it is also available in multiple forms. Users have the ability to scroll through comments and pictures as far back as the user's first posts. Profiles contain archived data that include everything the user has personally added to their page as well as posts or pictures that others have tagged them in or posted on their wall (Tokunaga, 2011). Because Facebook exists in an online space geography becomes obsolete. People are able to look at profiles and gather information about others anonymously and from anywhere in the world (boyd, 2008; Tokunaga, 2011).

Users of Facebook refer to this anonymous browsing as "creeping” or looking at someone's profile without leaving any comments or indications that you were there (Fox et al., 2013). Because information is easily accessible on Facebook, it is easy to secretly gain this information by creeping or surveying user profiles. The wealth of information available on Facebook makes it a good candidate for interpersonal electronic 
surveillance, which could be used as a way to attempt to reduce relational uncertainty.

This leads hypothesis three:

H3: Participants who use Facebook for interpersonal electronic surveillance will be less certain about their romantic relationship.

\section{Attachment}

When individuals enter into a romantic relationship, they do so with expectations about how the relationship will develop, regardless of certainty levels within the relationship (Honeycutt, Cantrill, \& Greene, 1983). These expectations can come from inner representations of relationships (Hazan \& Shaver, 1987). These representations are mental models of how a person expects a relationship to work (Bartholomew, 1990). When events occur that would make someone uncertain about his or her relationship, the reaction to the uncertainty is based on their attachment style (Jang et al., 2007). According to attachment theory, early experiences and interactions with caregivers help shape how individuals will behave in romantic relationships later in life. According to Hazan and Shaver (1987) the bond that arises between two adults in a romantic relationship is partially tied to the same behavioral system that elicits the connection between an infant and a caregiver: the attachment system.

Working models of the world and of the individual help to guide behaviors and expectations throughout their lifetimes. These models are used to help the individual understand events, forecast future events, and choose strategies to interact with other people (Bowlby, 1969). Working models are formed for both the self and others. Selfmodels are dynamic and reflect how loveable and worthy a person views themselves (Cassidy, 1990). These models also help determine self-esteem and self-perception 
(Bowlby, 1979). Working models of others focus on notions including expected reactions from attachment figures, acceptability of the individual in the eyes of the attachment figure, how supportive the attachment figure is when called upon for support, and the availability of the attachment figure (Feeney, Cassidy, \& Ramos-Marcuse, 2008). Working models of the self are separate from the relationship between the self and the attachment figure; however, if an individual has a secure relationship with their attachment figure, they will typically form a positive model of self (Cassidy, 1990). Therefore, the quality of the attachment relationship or security is interwoven with the assessment of the self (Cassidy, 1990). It is important to note that working models are constantly updating as an individual develops and the caregiver's working models should be in synch with the individual's to maintain a secure attachment (Bowlby, 1973). Infant attachment has typically been classified in terms of security. While working with infants Mary Ainsworth developed a classification system in which she divided infants into categories based on their attachment behaviors. These categories included securely and insecurely attached (Ainsworth \& Bowlby, 1991). Securely attached children are those who feel free to explore their environment and interact with strangers in the presence of their caregiver; when the caregiver leaves the infant will show signs of distress but when the caregiver returns the child will exhibit signs of happiness (Bretherton, 1992). A child typically develops a secure bond with a caregiver if their needs are consistently satisfied. This consistency results in a secure working model in which individuals are confident that their attachment figure will be available and responsive, whether that is in infancy, adolescence, or adulthood (Bretherton $\&$ Munholland, 1999). Secure individuals may come to seek and expect supportive 
relationships and behave in ways that prompt that support (Thompson, 1999). These individuals believe that they are worthy of love and trust others in their relationships. They are also not likely to worry unduly about being abandoned (Mikulincer \& Shaver, 2007).

In contrast to the secure category is the insecure category, which includes two specific types of attachment (Bretherton, 1992). The first is insecure-ambivalentattachment, which is displayed in infants as weariness to explore an environment and interact with strangers in the presence of the caregiver. The infant will become very distressed when the caregiver leaves but is unable to be calmed upon their return and remains hesitant to engage the environment (Bretherton, 1992). The second type of insecure attachment is insecure-avoidant- attachment, which is displayed in infants by the lack of exploring an environment regardless of the caregiver's presence or non-presence, the lack of emotion when the caregiver leaves or returns, and a similar treatment of both caregivers and strangers (Bretherton, 1992).

Although attachment theories were typically employed to explain the relationships between infants and caregivers, work has expanded to include multiple types of relationships beyond this dynamic, such as romantic relationships. Both dynamics include feeling safe when the attachment figure is near, feeling insecure when the attachment figure is not available, shared discoveries, a mutual fascination with one another, and baby talk (Hazan \& Shaver, 1987). Based on the assumption that romantic relationships are attachment relationships, the relationship between a partner and an individual may be similar to the relationship between a caregiver and an individual; having a responsive partner should result in secure characteristics. Additionally, the 
security experienced with a caregiver in early life might be an indicator of attachment within romantic relationships; individuals who were secure as children reflect on their secure working model and seek similar experiences in their relationship (Fraley, 2010).

Bartholomew and Horowitz (1991) further categorized insecure attachment into three areas in relation to adult attachment: preoccupied, fearful, and dismissive. (reordered to be in line w/what follows). Preoccupied attachment is equivalent to anxious-ambivalent attachment. When an attachment figure is inconsistent in meeting the needs of these ambivalent individuals or their availability fluctuates throughout time, a working model is developed in which the individual fears and expects rejection from their caregiver. These individuals tend to have high levels of anxiety but low levels of avoidance. These individuals generally have low opinions of self, believe they do not deserve love, and worry that they cannot count on an attachment figure to be there for them (Mikulincer \& Shaver, 2003).

When caregivers are neglectful repeatedly and consistently, a working model of others as untrustworthy and undependable is developed, and individuals are characterized as having high attachment-related avoidance. These individuals typically avoid romantic relationships because they do not want to be disappointed (Smith et al., 1999). There are two types of attachment that are high in avoidance: fearful and dismissive (Deniz, Harmata, \& Ari, 2005). Fearful individuals typically demonstrate high levels of both attachment-related anxiety and avoidance. Dismissive individuals tend to experience lower levels of anxiety and higher levels of avoidance (Fraley, 2010). Insecurely attached individuals expect less support from others due to their previous relationships marked by 
distrust and uncertainty, and therefore do not necessarily seek out support (Thompson, 1999).

According to Kirkpatrick and Davis (1994), securely attached individuals experience more satisfaction in relationships than those who are insecurely attached. This sentiment is echoed by Holland and colleagues (2012), who state that working models allow individuals to interpret the actions of their partner. In an ambiguous situation, secure individuals might be more trusting of their partner, whereas an insecure individual might misconstrue the event and become more distressed which could lead to less feelings of satisfaction (Holland et al, 2011). These differences in working models are likely to reinforce already existing ideas about relationships.

On this same note, Jang and colleagues (2007) found that attachment influenced relational uncertainty in later romantic relationships. Both attachment-related anxiety and avoidance were positively associated with self, partner, and relationship uncertainty. When uncertainty arose in a relationship, people who were not securely attached had difficulty communicating with their partner about their doubts in the relationship and the events that created the doubts (Jang et al., 2007). Although partners might avoid talking to each other about certain events face to face, they might use social networking sites to try to reduce uncertainty. For example, if a man discovered that his girlfriend was out at a party and her ex-boyfriend was there, he might check for pictures on Facebook to see if they were interacting. He might also check her comments to see if any of her friends mentioned the party. Similarly, a girlfriend might check her boyfriend's page to see if any of his statuses mentioned her or their relationship in a positive way. These are all passive 
information seeking strategies and do not require actually having to communicate with a partner directly.

Due to the nature of Facebook and the lack of context and tone in the written word, there is potential for those with high attachment-related anxiety to misread information or make a traumatic event out of nothing. When these traumatic events occur, the aforementioned strategies to get attention, reassurance, and care from their partner are used (Mikulincer \& Shaver, 2007). This leads to the fourth and fifth hypothesis:

H4: Attachment-related anxiety and avoidance will both have negative relationships with relational certainty.

Individuals high in attachment anxiety expect rejection and tend to be aware of cues that could lead to potential threats to the relationship. They also seek confirmation of the availability of their partner and actively behave in ways to reinforce the relationship. While gift giving might be a way to do this in the offline world, being tagged in pictures or mentioned in a partner's comments might reinforce the relationship online (Oldmeadow et al., 2013). Morey, Gentzler, Creasy, Oberhauser, and Westerman (2013) suggest that having public displays of affection on the internet could make individuals high in attachment anxiety feel more secure in their relationship. Referring back to these online displays might also comfort these individuals in later times of relational distress (Morey et al,. 2013).

H5A: Anxiety will be positively related to using Facebook for IES activities.

Additionally, individuals higher in attachment avoidance have been found to use other communication technologies for relationship maintenance less than those lower in 
avoidance (Jin \& Pena, 2010) which gives reason to believe that those same individuals with high attachment avoidance would use Facebook less than others. In fact, these individuals tend to avoid problems so it is unlikely that they would use Facebook for surveillance, which could potentially uncover problems in their relationship.

H5B: Avoidance will have less of an association with Facebook use for IES activities than anxious attachment.

\section{Self-Esteem}

Although Facebook has been linked positively to self-esteem, or the opinion a person has about their own self-worth, this relationship has mainly been explored in relation to general use of the website from a broad audience (Ellison, Steinfeld, and Lampe, 2007; Nadkarni \& Hofmann, 2012). The positive relationship between Facebook and self-esteem is due to the fact that social networks are used to provide social support, which is a "pathway by which social networks may influence physical and mental health status" (Berkman, Glass, Brissette, and Seeman, 2000, p. 846). Self-worth affects the ability to develop social relationships and "high social support increases self-esteem" (Kinnunen, Feldt, Kinnunen, \& Pulkkinen, 2008, p. 343). Forest and Wood (2012) suggest that people with low self-esteem view Facebook as a safe place for selfdisclosure; therefore they spend as much or more time using Facebook as people with high self-esteem. Kross, colleagues (2013) found contradictory results from those previously mentioned, suggesting that the more time users spend on Facebook, the lower their life satisfaction levels are over time. Self-esteem was not found to be a moderator for these changes in satisfaction. 
Lower self-esteem and depressed mood were found in youth that were seen as particularly invested in social networking sites (Neira \& Barber, 2014). These same findings were also true of females who had social networking sites compared to females who did not have the site (Neira \& Barber, 2014). These studies do not always take into account what Facebook is being used for. General Facebook use, or the amount of time one spends on Facebook, does not account for what people are doing on Facebook during this time. The same is true for Facebook intensity, a commonly used measurement; it measures overall use and attitudes, but not a specific activity.

Tazghini and Siedlecki (2013) found that certain activities on Facebook were related to self-esteem levels. People with higher self-esteem rated sharing pictures, thoughts, and ideas more positively than those with lower self-esteem (Tazghini \& Siedlecki, 2013). Specifically, untagging oneself in unflattering pictures was an activity associated more with low self-esteem. It was also discovered that people with lower selfesteem, felt a greater sense of belonging on Facebook and used the site to get to know new friends and communicate more easily (Tazghini \& Siedlecki, 2013). Tazghini and Siedlecki also found that users with lower self-esteem were more likely to accept friend requests from people they did not know. Perhaps using Facebook with surveillance in mind will yield different results on user self-esteem than just time spent on the site. This leads to research question five:

H6: Using Facebook for IES will have a negative relationship with user selfesteem.

In 2007, Ellison, Steinfeld, and Lampe found "using social networking sites may provide benefits for users who have low self-esteem and low life satisfaction" (p. 1143). 
Individuals who are secure in attachment also generally have higher self-esteem (Mickelson, Kessler, \& Shaver, 1997). This is because caregivers provided feedback promptly and effectively which lead to a formation of a positive self-concept and feelings of self-love and self-worth (Wu, 2009). Because caregivers were not prompt or dependable, individuals with insecure attachment develop a warped self-concept and see themselves as unlovable and unworthy, which can account for lower self-esteem $(\mathrm{Wu}$, 2009). Individuals with high attachment-related anxiety generally have positive views of other people, but tend to have negative views of themselves (Deniz, Harmata, \& Ari, 5005). They also tend to amplify their feelings of distress (Wu, 2009). Further, those with high levels of anxiety tend to rely on their peers to provide them with evaluations of themselves (Oldmeadow, Quinn, \& Kowert, 2013). These findings indicate that people with significant attachment-related anxiety have low levels of self-esteem or levels that may fluctuate due to evaluations from their peers. Individuals high in attachment-related avoidance tend to have low opinions of themselves as well as of others and they downplay or deny their feelings of distress (DiTamasso et al., \& Wu, 2009).

Individuals with high self-esteem are more easily able to interact with others and gain positive feedback which then helps them develop a better self-concept. Because insecure individuals are lacking self-esteem, they will not be as confident in interacting with others, therefore they will not receive positive feedback and their self-concept will remain distorted (Wu, 2009). Nadkarni and Hofmann (2012) suggest that self-esteem is strongly related with the need to belong and that social networking sites may be associated with higher levels of self-esteem. Therefore, being connected socially may increase or help maintain self-esteem in people with high attachment-related anxiety. 
While previous research has shown that self-esteem is related to general Facebook use and attachment anxiety (Oldmeadow et al., 2013) little research has shown a link between all three items. People with high attachment-related anxiety expect and become accustomed to rejection, so they are highly sensitive to the signs of both acceptance and rejection (Foster, Kernis, \& Goldman, 2007).

When threats to a relationship, whether real or imagined, bring about fear of losing the relationship, it is followed by the loss of self-esteem (Mathes, Adams, \& Davies, 1985). By turning to Facebook to reduce relational uncertainty, users with high attachment anxiety may hope to increase their self-esteem as well. This leads to the first and final research question of this study:

RQ1: Does attachment moderate the relationship between Facebook use for IES and levels of self-esteem? 


\section{Chapter 3: Methods}

Facebook and other social networking sites are becoming increasingly studied as they continue to be a staple in today's society. Research pertaining to relational uncertainty and Facebook is in its infancy; while there are a few studies on the topic, there is not a wealth of information available. The present study aimed to add to this increasing pool of knowledge and to provide insight into how Facebook and other social networking sites may affect users and their lives. This study also sought to gain insight on well-being and romantic relationships. In order to facilitate this study, a quantitative research approach was chosen. An online survey was chosen as the method for collecting data, as it was a convenient and easy way to distribute information to a large group of people. The survey was available to participants via the Qualtrics website and was accessible at the participants' convenience, until the specified completion date of March $17^{\text {th }}$.

A power analysis based on a study involving social networking sites and selfesteem $(M=35.17, S D=3.55)$ conducted by Gentile, Twenge, Freeman, and Campbell's (2012) and a pilot test conducted by the author of Tokunaga's (2011) IES scale $(M=$ $3.72, S D=1.52)$ indicated that a sample consisting of 257 participants would have enough statistical power (.80) to detect an association of .41 for a two-tailed test with a significance level set at.05. In order to attract this large number of participants, the researcher solicited multiple undergraduate courses in the communication department at a Pacific Northwest campus. Participants were read a brief five minute script (See Appendix A) detailing the nature of this study which asked for their participation. Announcements were posted to each class's course management system, which all of the 
students had access to. Participation was voluntary. Students who completed the survey received an incentive of extra credit for any course that offered the survey. Participants could only take the survey once; if more than one class offered the survey as an extra credit incentive, students were given the chance to complete another assignment that required a similar amount of time in order to receive extra credit for the additional courses. The survey was available for participants to take for approximately two weeks from March $3^{\text {rd }}$ until March $17^{\text {th }}$. Participants' identities were kept anonymous, and participation was confidential. Participants read an informed consent (See Appendix B) page before they were able to access the survey.

\section{Participants}

The population for this study was students age 18 and older. Two hundred ninetynine people started the survey; however, only 288 made it past the informed consent portion. Sixteen participants did not have Facebook, which was a requirement for the study, and were directed to a message informing them that they were not eligible for participation. Overall, the sample consisted of 261 participants, which met the previously established number of participants needed for power. Sixty-six percent of participants were women $(N=173)$, and two percent $(N=5)$ did not respond to the question about gender. The mean age of participants was 24 , the youngest participant was 18 , and the oldest was 73. Forty-eight percent $(N=126)$ of participants were seniors, 36 percent $(N=$ 94) were juniors, 10 percent $(N=26)$ were sophomores, 4 percent $(N=6)$ were freshman, and 2 percent $(N=3)$ reported a status of other. Sixty-seven percent of participants $(N=$ 174) identified as Caucasian, 6 percent $(N=16)$ identified as either African American or Hispanic, 13 percent $(N=35)$ identified as Asian, and 14 percent as other. 
Participants in a current relationship $(N=174)$ were asked to report how many months they had been in the relationship $(M=27.5, S D=21.5)$, and the median was 20 months. For this study, participants did not need to be in a current relationship and could also refer to their most recent relationship. Participants who referred to a previous relationship $(N=85)$ were asked how long their relationship had lasted $(M=17.65, S D=$ 16.60), and the median was 11 months. These participants were also asked how many months ago their relationship ended $(M=17.19, S D=17.41)$, and the median was nine months. The data from participants currently in a relationship is emphasized below because these participants could answer questions about a relationship that was in the present, and their answers may be more accurate.

\section{Procedure}

To test whether using Facebook for surveillance corresponded with relational uncertainty, attachment-related anxiety and avoidance, and/or self-esteem, a survey containing multiple measurement instruments related to each variable was used. A script explaining the procedure and the extra credit incentive was given to professors and read aloud to each class by the researcher. The survey was hosted on the website, Qualtrics, which was accessible on any computer with internet access. If participants met the requirements of having a Facebook account and being at least 18 years of age, they were able to continue to the actual survey and complete the different measurement scales and demographic information, which took approximately 15-20 minutes.

\section{Measures}

The survey used for this study consisted of pre-existing scales to measure attachment-related anxiety and avoidance, relational uncertainty, self-esteem, and 
Facebook use for surveillance. Participants were asked if they currently displayed their relationship status on Facebook or if they did in their most recent relationship, and if their status is or was linked to their partner's profile. Questions relating to general Facebook use were asked as well.

Facebook use. General Facebook use and Facebook use for interpersonal electronic surveillance were both measured for this study. General use was measured by multiplying the number of days per week by minutes per day that participants actively used Facebook, i.e. not just having the site open in a browser but looking at or posting content, chatting, or using some other function of the site. Three questions were used to gather this information and included (1) "In a typical week, how many days do you access your Facebook account," (2) “On a typical day, about how many times do you check your Facebook account," and (3)" On a typical day, about how many minutes do you spend actively using Facebook." Participants were asked to answer yes or no to two questions pertaining to their relationship status (1) "Is your relationship status listed on Facebook" and (2) "Is your relationship status with your partner displayed on Facebook so that your profiles are connected." Participants were also asked if they were referring to a current or recent relationship.

To measure interpersonal electronic surveillance, Tokunaga's (2011) interpersonal electronic surveillance (IES) scale for SNSs (See Appendix C) was used. The scale was modified to measure Facebook specifically instead of multiple social networking sites. This scale consists of 12 statements measured on a 7-point Likert scale from 1 - strongly disagree to 7 - strongly agree. Statements include (1) "I visit my partner's Facebook page often," (2) “When visiting my partner's Facebook page, I read 
the new posts of his/her friends," (3) "I often spend time looking through my partner's Facebook pictures," (4) "I pay particularly close attention to Facebook news feeds that concern my partner," (5) "I notice when my partner updates his/her Facebook page," (6) "I am generally aware of the relationships between my partner and his/her Facebook friends," (7) "I try to read comments my partner posts on mutual friends' Facebook walls," (8) "I am generally aware of my partner's Facebook activities," (9) "I peruse my partner's Facebook page to see what he/she's up to," (10) “I know when my partner hasn't updated his/her Facebook page in a while," (11) "I try to monitor my partner's behaviors through his/her Facebook page," and (12) “I explore my partner's Facebook page to see if there is anything exciting or new." The scores were averaged and higher means reflected higher usage of Facebook for surveillance. Cronbach's alpha for this scale was .93 .

Relational Uncertainty. To measure uncertainty within a relationship Knobloch and Solomon's (1999) relational uncertainty scale (See Appendix C) was used. The modified version of this scale consists of 20 questions divided into three subsections: self-uncertainty, partner uncertainty, and relationship uncertainty. The directions of the questions on this scale were reversed so that all items used were in the same direction, where lower numbers were reflective of a low level of agreement. Because of this, results were reported by levels of certainty rather than uncertainty. All subsections of the relationship uncertainty scale were measured on a 6-point Likert-type scale from 1 completely uncertain to 6 - completely certain. Higher scores were indicative of more certainty in a relationship.

The self-subscale asked participants to rate their level of certainty with the 
following six statements, (1) "Your commitment to the relationship," (2) "Your feelings about the relationship," (3) "How much you are romantically interested in your partner," (4) "Your view of this relationship," (5) "Whether or not you want this relationship to last," and (6) "Your goals for the future of this relationship." Cronbach's alpha for the self-subscale was .94 . The same questions were asked about the partner's commitment for the partner subscale. Cronbach's alpha for the partner sub scale was .95 . The relationship scale asked participants to rate their level of certainty with the following eight statements, (1) "What you can or cannot say to each other in this relationship," (2) "The norms for this relationship," (3) "Whether or not you and your partner feel the same way about each other," (4) "The current status of the relationship," (5) "The definition of this relationship," (6) "How you and your partner would describe this relationship," (7) "Whether or not you and your partner will stay together," and (8) "The future of this relationship." Cronbach's alpha for the relationship subscale was .94. Each subsection could be used on its own or the whole scale could be used for overall certainty; the higher the score the more certainty about the relationship. Cronbach's alpha for the uncertainty scale as a whole was 97.

Attachment. The experiences in close relationships scale - revised (ECR - R; Fraley, Waller, \& Brennan, 2000) was used to measure attachment-related anxiety and avoidance (See Appendix C), which consists of 36 questions divided into two halves and measured on a 7-point Likert scale from 1 - strongly disagree to 7 - strongly agree. The first half of the scale measures attachment-related anxiety and asked participants to rate their agreement with the following 18 statements, (1) "I'm afraid that I will lose my partner's love," (2) "I often worry that my partner will not want to stay with me," (3) "I 
often worry that my partner doesn't really love me," (4) "I worry that romantic partners won't care about me as much as I care about them," (5) “I often wish that my partner's feelings for me were as strong as my feelings for him or her," (6) "I worry a lot about my relationships," (7) "When my partner is out of sight, I worry that he or she might become interested in someone else," (8) “When I show my feelings for romantic partners, I'm afraid they will not feel the same about me," (9) "I rarely worry about my partner leaving me," (10) "My romantic partner makes me doubt myself," (11) "I do not often worry about being abandoned," (12) "I find that my partner(s) don't want to get as close as I would like," (13) “Sometimes romantic partners change their feelings about me for no apparent reason," (14) "My desire to be very close sometimes scares people away," (15) "I'm afraid that once a romantic partner gets to know me, he or she won't like who I really am," (16) "It makes me mad that I don't get the affection and support I need from my partner," (17) "I worry that I won't measure up to other people," and (18) "My partner only seems to notice when I'm angry." Two questions on this half of the scale, nine and eleven were reverse-coded so that the all response options were worded in the same direction. The scores were averaged to create a score for attachment-related anxiety. Higher scores indicated higher levels of anxiety, and lower scores were more consistent with secure attachment. Cronbach's alpha for the anxiety portion of the scale was .95 .

The second half of the scale measured attachment-related avoidance and also contained 18 statements on the same 7-point Likert scale. Statements included, (1) "I prefer not to show a partner how I feel deep down,” (2) “I feel comfortable sharing my private thoughts and feelings with my partner," (3) "I find it difficult to allow myself to depend on romantic partners," (4) "I am very comfortable being close to romantic 
partners," (5) "I don't feel comfortable opening up to romantic partners," (6) "I prefer not to be too close to romantic partners," (7) "I get uncomfortable when a romantic partner wants to be very close," (8) "I find it relatively easy to get close to my partner," (9) "It's not difficult for me to get close to my partner," (10) "I usually discuss my problems and concerns with my partner," (11) "It helps to turn to my romantic partner in times of need," (12) "I tell my partner just about everything," (13) "I talk things over with my partner," (14) "I am nervous when partners get too close to me," (15) "I feel comfortable depending on romantic partners," (16) "I find it easy to depend on romantic partners," (17) "It's easy for me to be affectionate with my partner," and (18) "My partner really understands me and my needs." The majority of these statements, 2, 4, 8, 9, 10, 11, 12, $13,15,16,17$, and 18 , were recoded so that all questions were in the same direction. Cronbach's alpha for the avoidance portion of the attachment scale was .91 .

Self-esteem. Self-esteem was measured using the Rosenberg self-esteem scale (Rosenberg, 1965; See Appendix C) which asked participants to rate their agreement level with the following ten statements, (1) "I feel that I am a person of worth, at least on an equal plane with others," (2) "I feel that I have a number of good qualities," (3) "All in all, I am inclined to feel that I am a failure," (4) "I am able to do things as well as most people," (5) “I feel I do not have much to be proud of," (6) "I take a positive attitude towards myself," (7) “On the whole, I am satisfied with myself," (8) "I wish I could have more respect for myself," (9) “I certainly feel useless at times," and (10) “At times I think I am no good at all.” Negative statements, which included numbers 3, 5, 8, 9, and 10, were reverse coded so that all ten statements measured attitudes in the same direction. Agreement was measured on a Likert-type scale from 1- strongly disagree to 4- strongly 
agree. The higher the score for the entire scale, the higher a participant's self-esteem.

Cronbach's alpha was .91.

Table 1

Descriptive Statistics of Scales

\begin{tabular}{lrr}
\hline Scale M & SD & \\
\hline Relational Certainty & 107.7 & 16.7 \\
Self-Certainty & 32.5 & 5.3 \\
Partner Certainty & 32.8 & 5.1 \\
Relationship Certainty & 42.4 & 7.3 \\
Facebook Surveillance & 3.7 & 1.3 \\
General Facebook Use & 181.2 & 185.6 \\
Attachment Anxiety & 2.5 & 1.1 \\
Attachment Avoidance & 2.3 & 1.1 \\
Self-Esteem & 32.4 & 5.9 \\
\hline
\end{tabular}

Relational Certainty could range from 20 to 120 , Self-Certainty could range from 6 to 36, Partner Certainty could range from 6 to 36, Relationship Certainty could range from 8 to 48, Facebook Surveillance could range from 1 to 7, General Facebook use could range from 0 to 1260, Attachment Anxiety could range from 1 to 6, Attachment Avoidance could range from 1 to 6, and Self-Esteem could range from 10 to 40.

\section{Analysis}

Hypothesis one stated that users who had their relationship status displayed on Facebook would be more certain about their relationships than those who did not display their relationship status. Because relationship status on Facebook was determined by a yes or no response and relational uncertainty was determined on an interval scale, an independent samples $t$-test was run to determine if there was a difference in certainty levels between couples in a current relationship who displayed their relationship status and those who did not. Additional independent samples $t$-tests were run for each subsection of the relational uncertainty scale as well. An independent samples $t$-test was 
also run to determine if a similar difference existed concerning relational uncertainty and relationship status on Facebook for those who referred back to a previous relationship. Hypothesis two stated that couples who did have their relationship status displayed and linked to their partner's page would be more certain about their relationship than those who had their relationship status displayed but not linked to their partner's profile, as well as those who did not have their status listed at all. Because relationship status on Facebook was determined by a yes or no response and relational uncertainty was determined on an interval scale, an independent samples $t$-test was run to determine if there was a difference in certainty levels between couples who displayed their relationship and had their profile linked to their partner's page and those who displayed their status but did not have their profile linked to their partner's page. A correlation test was run to determine if relational certainty was negatively related to using Facebook for interpersonal surveillance, as suggested in hypothesis three.

Hypothesis 4A, which stated that attachment anxiety would be negatively related to relational certainty, was tested using a correlation since attachment-related anxiety and relational uncertainty were all measured using interval level measures. Hypothesis 4B, which stated that attachment avoidance would be negatively related to relational certainty, was also tested using a correlation since avoidance was also measured with an interval scale. Hypothesis $5 \mathrm{~A}$, stated that attachment anxiety would be positively related to using Facebook for IES activities and was tested with a correlation. Hypothesis 5B, which suggested that attachment avoidance was less associated to using Facebook for IES activities than attachment anxiety, was also tested with a correlation. Self-esteem was also measured on an interval scale, so to test research hypothesis six regarding a negative 
relationship between Facebook use for IES and self-esteem levels, another correlation was run. To test RQ1, regarding attachment anxiety and avoidance as a moderator of Facebook use for interpersonal electronic surveillance and user self-esteem, a regression was run for both anxious and avoidance related attachment and the other two variables previously mentioned. Alpha levels for each test were set at .05 a priori. 


\section{Chapter 4: Results}

\section{Preliminary Results}

As previously mentioned, the final sample for this study consisted of 261 participants, 70.5 percent $(\mathrm{N}=184)$ of whom initially referred to a current relationship while the remaining 75 referred to a previous relationship. Two participants did not answer the question regarding relationship status. Because this study looked at how Facebook might be used as a source of interpersonal electronic surveillance, it was advantageous for participants to refer to a relationship where both they and their romantic partner each had a separate Facebook account. One hundred sixty-three of the participants who initially stated that they would be referring to a current relationship had a partner currently on Facebook. The remaining 21 participants were asked if they had ever been in a relationship where both parties had a Facebook account. Ten participants answered yes to this question and were asked to refer back to that relationship for this survey while the remaining 11 had never been in a relationship with a partner who had a Facebook account, at least at the same time that the participant had an account. These remaining 11 participants were asked to refer to their current relationship and did not receive questions pertaining to Facebook surveillance or linkage of their profile page with their partner's profile page.

Participants who were in a current relationship with a partner who also had Facebook $(\mathrm{N}=163)$ were asked if their relationship status was displayed on Facebook, 66.9 percent $(\mathrm{N}=109)$ said that their relationship status was displayed on Facebook, and 93.6 percent of these participants reported that their profile was linked to their partner's profile. While 85 participants referred to a past relationship for this survey, 10 did not 
answer if their relationship status was displayed on Facebook. Skip logic was utilized, so that participants who did not have their status displayed on Facebook were not asked if that status was then linked to their partner's profile. For the participants that did answer the relationship status question $(\mathrm{N}=75), 52$ percent reported having their relationship status displayed on Facebook and 82.1 percent of these participants also had their Facebook profile page linked to their partner's profile page. Overall, 261 participants provided usable data for the current study, 238 of whom answered the question regarding their relationship status being displayed on Facebook. One hundred sixty-three relationships were considered as current because the relationship was active and both members in the relationship had an active Facebook account. Seventy-five relationships were considered previous because these relationships were not still active, but both partners did have Facebook accounts when the relationship was active. Both groups of participants, either in current or previous relationships, were used for analysis but current relationships were the main focus since they were active and did not require participants to refer back to events that happened in the past in order to answer questions on the survey.

\section{Facebook Relationship Status and Relational Uncertainty}

Hypothesis one suggested that there would be a difference in relational certainty between participants who had their relationship status displayed on Facebook and those who did not have their relationship status displayed on Facebook. The relational uncertainty scale was used as a whole and also broken down into three subsections. As hypothesis one suggested, an independent samples $t$ test revealed that relational certainty was higher for participants in current relationships who had their relationship status 
displayed on Facebook $(M=113.2, \mathrm{SD}=12.4)$ than for those participants who did not have their status displayed $(\mathrm{M}=100.1, \mathrm{SD}=18.3), t(78.1)=4.76, \mathrm{p}<.001$. The results were similar for each subsection of the relational certainty scale concerning participants in current relationships. For the self-certainty scale, an independent samples $t$ test showed that participants with their relationship status displayed on Facebook $(\mathrm{M}=34.1, \mathrm{SD}=$ 4.1) had more self-certainty those without their status displayed $(\mathrm{M}=30.1, \mathrm{SD}=5.9), t$ $(78.1)=4.45, \mathrm{p}<.001$. Another independent samples $t$ test also revealed that partner certainty was higher for participants whose relationship status was displayed on Facebook $(\mathrm{M}=34.4, \mathrm{SD}=3.5)$ and those whose status was not displayed $(\mathrm{M}=30.8, \mathrm{SD}$ $=5.7), t(73.3)=4.14, \mathrm{p}<.001$. A final independent samples $t$ test revealed that relationship certainty was higher for those who had their relationship status displayed on Facebook $(\mathrm{M}=44.7, \mathrm{SD}=5.6)$ and those who did not have their relationship status displayed $(\mathrm{M}=39.1, \mathrm{SD}=7.9), t(80.1)=4.62, \mathrm{p}<.001$. Because more relational certainty existed for participants who did have their relationship status displayed on Facebook versus those who did not, hypothesis one was supported.

Relationship status and relational certainty for participants who referred to a previous relationship were measured with the same instruments as current relationships. However, independent samples $t$ tests failed to determine a significant difference between those who had their relationship status displayed on Facebook versus those who did not, $t$ $(72)=.83, p=.41$. This lack of difference between groups was true for each subsection of the relational certainty scale as well.

\section{Displayed Relationship Status versus Linked Profiles}


Hypothesis two suggested that linking a Facebook profile with a partner's profile, such that one profile is accessible from the other by clicking on the partner's name ("John Doe is in a relationship with Jane Doe"), would lead to more relational certainty than just displaying a relationship status. Participants in a current relationship who had their relationship status displayed on Facebook were also asked if they had their Facebook profile and status linked to their partner's profile page. Only seven people who had their status displayed did not have it linked. Because of this, hypothesis two, which expected a difference to exist, was not supported. However, this points to another important takeaway for this study; displaying and linking a relationship on Facebook go hand in hand. Rarely do people display their relationship without also linking it with their partner's page.

\section{Relational Uncertainty and Interpersonal electronic Surveillance (IES)}

Hypothesis three suggested that relational certainty would be negatively associated with using Facebook as a way to survey romantic partners, i.e. the more Facebook was used for surveillance of a partner the less certain a person would be about that relationship. However, a correlation test failed to find a relationship between these two variables, $r(160)=-.01, p=.84$ which means that hypothesis three was not supported, and there appears to be no relationship between using Facebook for surveillance and the amount of certainty within that relationship.

\section{Relational Uncertainty and Attachment}

Attachment anxiety. Hypothesis 4A stated that attachment anxiety would be negatively related to relational certainty, such that as the level of one item increased or decreased, the other would move in the opposite direction. A correlation test revealed a 
negative correlation between anxiety and relational certainty, $r(171)=-.58, \mathrm{p}<.001$.

Because the sub-sections of the relational certainty scale were not normally distributed, a Spearman correlation was run for each section with similar results to the overall certainty scale. A moderate negative correlation existed between attachment anxiety and selfcertainty, $r_{s}(171)=-.56, \mathrm{p}<.001$, partner certainty, $r_{s}(171)=-.64, \mathrm{p}<.001$, and relationship certainty, $r_{s}(171)=-.65, \mathrm{p}<.001$. Therefore, hypothesis $4 \mathrm{~A}$ was supported, which means that attachment-related anxiety and relational certainty were indeed related.

Attachment avoidance. Hypothesis $4 \mathrm{~B}$ was similar to $4 \mathrm{~A}$ in that it assumed that attachment avoidance would be negatively associated with relational certainty. The two items were negatively correlated, $r(170)=-.72, \mathrm{p}<.001$. Similar results were found using Spearman correlations for the separate sections of the relational certainty scale. Negative moderate correlations were found between attachment avoidance and selfcertainty, $r_{s}(170)=-.64, \mathrm{p}<.001$, partner certainty, $r_{s}(170)=-.63, \mathrm{p}<.001$, and relationship certainty, $r_{s}(170)=-.71, \mathrm{p}<.001$. These results provide support for hypothesis $4 \mathrm{~B}$, regarding a negative relationship between attachment avoidance and relational certainty.

\section{Attachment and Interpersonal electronic Surveillance (IES)}

Attachment anxiety. Hypothesis 5A suggested that using Facebook for surveillance of a romantic partner would have a positive relationship with attachment anxiety. This would mean that higher use of Facebook for surveillance was related to higher attachment-related anxiety, or that lower attachment-related anxiety was related to lower surveillance via Facebook. The two items were positively correlated, although the correlation was low, $r(159)=.17, \mathrm{p}<.05$. This means that hypothesis 5 A was supported 
and as Facebook surveillance or anxiety moved in one direction, the other item moved in the same direction.

Attachment avoidance. Hypothesis 5B predicted that attachment avoidance would not be as highly associated as attachment anxiety with using Facebook as a form of surveillance. Therefore, if a relationship did exist between avoidance and surveillance it would not be as strong as the relationship between anxious attachment and using Facebook for IES. In fact, no correlation was found between the two items, $r(159)=$ $.005, \mathrm{p}=.95$, which means that hypothesis $5 \mathrm{~B}$ was supported.

\section{Self-Esteem and Interpersonal electronic Surveillance (IES)}

Hypothesis six expected to find a negative relationship between self-esteem and Facebook use for IES, such that when self-esteem increased or decreased IES levels would move in the opposite direction, or when IES increased or decreased self-esteem would move in the opposite direction. In order to test this, a correlation test was run, and a relationship that was not quite significant was found, $r(160)=-.14, \mathrm{p}<.09$. Because this marginal finding may have been due to a lack of power when including current relationships only, a correlation was also run using the entire sample (including current and previous relationships). A negative correlation was found, $r(231)=-.15, \mathrm{p}<.05$. Although the relationship was not strong, self-esteem and Facebook use for IES were negatively associated for the full sample.

\section{Attachment as a Moderator}

Attachment anxiety. The research question for this study suggested that attachment-related anxiety would moderate the relationship between Facebook use for Interpersonal electronic surveillance (IES) and self-esteem. In order to run a factorial 
ANOVA, attachment anxiety and Facebook surveillance were dichotomized. Low values for anxiety ranged from 0 to the mean, which was 2.83 , and high values ranged from the mean to 7. Low values for Facebook surveillance ranged from 0 to the mean, which was 3.78, and high values ranged from the mean to 7 . A main effect existed between attachment anxiety and self-esteem, $F(1,160)=73.1, \mathrm{p}<.001$. A main effect did not exist between Facebook surveillance and self-esteem, $F(1,160)=2.4, \mathrm{p}=.12$.

Additionally, anxiety did not have a moderating effect on the relationship between Facebook surveillance and self-esteem, $F(1,160)=2.8, \mathrm{p}=.10$. The means and standard deviations for all groups are shown below (in table 2).

Table 2

Levels of Self-Esteem by Attachment Anxiety and Facebook Surveillance

\begin{tabular}{llll}
\hline Group & Mean & N & SD \\
\hline Low Anxiety, Low Surveillance & 34.48 & 54 & 4.97 \\
Low Anxiety, High Surveillance & 34.57 & 56 & 4.67 \\
High Anxiety, Low Surveillance & 28.81 & 22 & 5.60 \\
High Anxiety, High Surveillance & 26.17 & 29 & 4.15 \\
\hline
\end{tabular}

Attachment avoidance. The research question also asked if attachment-related avoidance would moderate the relationship between Facebook use for IES and selfesteem. In order to run a factorial ANOVA, attachment avoidance and Facebook surveillance were dichotomized. Low values for avoidance ranged from 0 to the mean, which was 2.53, and high values ranged from the mean to 7 . A main effect existed between attachment avoidance and self-esteem, $F(1,160)=47.7, \mathrm{p}<.001$. A main effect 
was not observed between Facebook for IES and self-esteem, $F(1,160)=2.3, \mathrm{p}=.13$.

Similarly, attachment avoidance was not found to moderate the relationship between Facebook surveillance and self-esteem, $F(1,160)=1.2, \mathrm{p}=.27$. The descriptive statistics for each group are shown below (in table 3).

Table 3

Levels of Self-Esteem by Attachment Avoidance and Facebook Surveillance

\begin{tabular}{llll}
\hline Group & Mean & N & SD \\
\hline Low Avoidance, Low Surveillance & 34.38 & 53 & 5.21 \\
Low Avoidance, High Surveillance & 34.01 & 57 & 4.96 \\
High Avoidance, Low Surveillance & 29.30 & 23 & 5.41 \\
High Avoidance, High Surveillance & 27.00 & 28 & 5.19 \\
\hline
\end{tabular}

\section{Post Hoc Results}

Facebook relationship status and attachment. An independent samples $t$ test revealed a significant difference in relational uncertainty between participants in a current relationship who displayed their relationship status on Facebook and those who did not, as suggested in hypothesis 1 . This $t$ test also revealed that the group who did not have their relationship status displayed $(M=100.1, S D=18.3)$ had a larger variance in their standard deviations from the mean than the group who did have their status displayed $(M$ $=113.2, S D=12.4)$. Because of this disparity, an additional independent samples $t$ test was run to see if there would be a difference in means between the same two groups regarding attachment-related anxiety and avoidance, assuming that the group without their relationship status displayed on Facebook would have a larger mean and larger 
standard deviation on both attachment anxiety and avoidance than the group with their relationship status displayed. For attachment anxiety, an independent samples $t$ test revealed a significant difference between those with their relationship status displayed $(M$ $=2.21, S D=.93, N=108)$ and those without their relationship status displayed $(M=3.01$, $S D=1.20, N=54), t(86.03)=4.3, \mathrm{p}<.001$. As far as attachment avoidance and relationship status, an independent samples $t$ test showed a significant difference between those in a current relationship with their status displayed on Facebook $(M=1.9, S D=$ $.97, N=107)$ and those without their status displayed $(M=2.85, S D=1.12, N=54), t$ $(94)=-5.29, \mathrm{p}<.001$

Attachment and self-esteem. Attachment-related avoidance and anxiety have both been shown to have a negative relationship with self-esteem, as previously mentioned in this study; as either self-esteem or attachment anxiety or avoidance increase or decrease, the other will move in the opposite direction. Correlation tests support past research for both anxiety, $r(170)=-.55, \mathrm{p}<.001$ and avoidance, $r(170)=-.50, \mathrm{p}<.001$.

General Facebook use and self-esteem. Previous research has found conflicting results as far as well-being and Facebook are concerned. While Facebook for IES and self-esteem were negatively related, a Spearman correlation revealed no relationship between general Facebook use and self-esteem, $r_{s}(170)=-.03, \mathrm{p}=.66$.

General Facebook use and relational uncertainty. While hypothesis three suggested that a negative relationship would exist between certainty in a relationship and Facebook surveillance, no significant relationship was found. No significant relationship was found between general Facebook use, or time spent actively on Facebook, and relational uncertainty. However, when splitting the groups into those who had their 
relationship status displayed on Facebook and those without their status displayed, a negative relationship was found between general Facebook use and relational certainty for the group with their status displayed, $r_{s}(106)=-.26, \mathrm{p}<.01$. A negative relationship was also found between general Facebook use and self-certainty in the group with their status displayed $r_{s}(106)=-.25, \mathrm{p}<.01$, as well as partner certainty, $r_{s}(106)=-.35, \mathrm{p}<$ .001 , and relationship certainty, $r_{s}(106)=-.23, \mathrm{p}<.05$. This means that for participants with their relationship status displayed on Facebook, as Facebook use or relational certainty increased the other item decreased or as one item decreased the other increased. 


\section{Chapter 5: Discussion}

The purpose of this study was to investigate possible relationships between using Facebook as a tool for interpersonal electronic surveillance (IES), relational uncertainty, attachment behaviors, and self-esteem. The first hypothesis of this study explored how relational uncertainty would be impacted by displaying a romantic relationship on Facebook. Certainty was higher for those who did display their relationship; however, there was no difference between those who simply displayed their relationship status and those who displayed and linked their profile to their partner's profile. No association was found between Facebook surveillance and relational uncertainty; however a positive relationship did exist between Facebook surveillance and attachment anxiety. Further concerning attachment anxiety, a negative correlation was found between anxiety and both relational certainty and self-esteem. Negative correlations also existed between attachment avoidance and both self-esteem and relational certainty. However, neither of these attachment dimensions was found to moderate the relationship between self-esteem and Facebook surveillance. The results of this study seem to indicate that using Facebook differs per individual and might not be just a way to pass the time. All of the findings are examined in further detail in the remainder of this chapter.

\section{Facebook and Relational Uncertainty}

Displaying a relationship and certainty. Participants in a current relationship

who displayed their relationship status on Facebook had higher levels of certainty regarding their relationship when compared to those who did not display their status. This was true of certainty as a whole and of all three areas of certainty, including self, partner, and relationship certainty. The idea of being "Facebook official," or displaying a 
relationship on Facebook has started to become a norm for couples (Fox, Warber, \& Makstaller, 2013). This declaration sends a sign that a relationship exists, and neither party is available to date anyone else. Displaying a relationship on Facebook, and especially linking it with a partner so that both pages are connected, is a straightforward way of presenting a relationship, and this unambiguous statement could lead to the heightened certainty in those participants with their relationship status displayed. It is also possible that individuals who are more certain of their relationship are more likely to display and link their status. If an individual displays their relationship status, it could be assumed that the person is certain of their role within that relationship, and a similar assumption can be made of a partner if he or she is willing to display and link their relationship status.

Displaying versus linking. While relational uncertainty was different between those who displayed their relationship status on Facebook and those who did not, hypothesis two suggested that there would be a similar difference in certainty between participants who simply displayed their status and those who linked their status and profile with their romantic partner's profile. Participants who had their Facebook profile linked with their partner's profile were overall more certain of their relationship than those who did not have their relationship displayed at all, but a difference was not found in certainty between participants with their profiles linked and participants with only their status displayed. This lack of difference is largely due to the fact that only seven people who displayed their relationship did not link their profile with their partner's. Out of the 109 participants in a current relationship who displayed their relationship status on Facebook, 102 also had their status linked with their partner. This large number of people 
seems to point to a prominent trend of either displaying and linking a relationship on Facebook, or not displaying a relationship on Facebook at all.

Displaying a relationship on Facebook appears to be indicative of more certainty of that relationship, as the results from this study show. When examining the differences in relational uncertainty for participants who displayed and did not display their relationship status on Facebook, not only was a difference found for the means between the two groups, but a large difference was also found between standard deviations, or the variation of the responses from the average answer. The average distance from the mean was nearly a third more for those without their status displayed than those who did have their status displayed for the entire certainty scale. Disparities in standard deviations were found between the groups for each subsection of the certainty scale as well. This indicates that participants who did not display their relationship on Facebook were less consistent in their answers. These inconsistencies could have occurred for many reasons. First, norms within each relationship vary, so while some individuals might be happy not to display their relationship status others might experience changes in relational certainty if they want to link their status but their partner does not. Secondly, if individuals were uncertain about their relationship, it makes sense that their responses would be inconsistent; this is the nature of uncertainty. There might be certain aspects of the relationship that are definitive which could be why the relationship has continued to progress, but other areas are unknown. One reason for this relational uncertainty could be lack of communication about uncertain aspects. Attachment behaviors could explain this; relational uncertainty could lead to attachment avoidance in which the individual attempts to avoid addressing potential problems within the relationship, whereas 
relational uncertainty could lead to heightened anxiety due to the fear of rejection from a partner.

Displaying and attachment. Because of the larger variance seen in the responses from participants without their relationship status displayed, an additional test was run to determine if attachment would differ between groups. Ambiguity is problematic for individuals with insecure attachment, who are more likely to misconstrue these ambiguous messages (Holland et al, 2011), which relates to uncertainty in relationships (Brashers, 2001). Not having a relationship status on Facebook could be interpreted differently depending on attachment-related anxiety or avoidance, with anxious individuals seeing it as a sign that their relationship is not stable which could perpetuate feelings of uncertainty. Differences in both attachment anxiety and avoidance were found between those who displayed their relationship status and those who did not. Participants who had their relationship status displayed on Facebook reported less anxiety and less avoidance with their current partner than those without their status displayed. This could mean that people who feel more secure in their attachment within a particular relationship are more likely to post their relationship status, or that posting a relationship status could help make someone feel more secure in their relationship. Since relational certainty was higher for participants with their relationship status displayed on Facebook, and higher relational certainty is associated with lower levels of anxiety and avoidance, it makes sense that participants without their status displayed would be less certain of their relationship and report higher levels of insecure behaviors. Higher levels of certainty and security for those who use the site as a way to display their relationships seem to indicate 
that people are indeed using the site for different reasons, which could be either because of their personal characteristics or an impact on these personality traits.

\section{Facebook and Relational Uncertainty}

Facebook surveillance. Facebook lends itself well as a venue for reducing uncertainty due to the plethora of personal information that users provide about themselves on the website. Because of the popularity of Facebook and the amount of personal information it provides, this study tested whether using the site as a source of interpersonal electronic surveillance (IES) would be associated with relational uncertainty. However, this was not the case. Surprisingly, no relationship was found between Facebook use for IES and relational certainty. Passive strategies are most commonly employed by Facebook users to decrease uncertainty (Antheunis et al., 2009), such as looking at a partner's messages, photos, comments etc. Interactive strategies have proven to be more productive in decreasing relational uncertainty though (Antheunis et al., 2009). Perhaps the type of surveillance that occurred among participants was more passive rather than interactive, and only reinforced the beliefs participants already had about their current relationship. Individuals might also avoid updating their page with materials that would induce worrying in their partners, even if worrying was justified. For example, if a girlfriend went to a party that her boyfriend asked her not to attend, she might simply post a status stating that she was out with friends rather than posting about the party. If her boyfriend checked her page, then he would see that she was with friends and maybe not question her activities beyond that. This example might not change levels of certainty about the relationship, but reinforce the amount of certainty that already exists. 
General Facebook use. General Facebook use and Facebook use for IES were positively correlated. It makes sense that the more time an individual spends on Facebook, the more they would be likely to survey their partner, even if it was unintentional. If a relationship is linked to a partner's page, an individual has access to their partner's page from their own page and while they might not have originally intended to check out their partner's page, seeing their partner's name and being able to access their partner's profile by simply clicking the link on their name, allows them to easily begin surveying. Similar to Facebook for IES, no relationship was found between general Facebook use, or active time spent on Facebook, and relational uncertainty, until the participants in a current relationship were split into groups by whether or not they displayed their status on Facebook. Splitting the groups revealed that the more time an individual with their status displayed spent on Facebook the more uncertain they were about their relationship. Participants with their status displayed on average spent nearly 20 minutes more per week on Facebook.

Being active on Facebook could take away time from communication that would occur in person between actual partners. This lack of face-to-face communication could increase uncertainty within the relationship (Gibbs et al., 2011), which could explain why general Facebook use and certainty were negatively related. Added to this is the fact that nonverbal cues are also limited on Facebook, making uncertainty reduction more difficult online than in person (Gibbs et al., 2011). Realistically, time spent on Facebook is probably not strictly dedicated to looking at a partner's page. In fact, the newsfeed is constantly updating with information about all Facebook friends. Within this flow of information, are news of engagements, marriages, and pregnancies as well as pictures 
from dates and updates about others' relationships. This look into the relationships of friends could impact an individual's sense of certainty about their own relationship if she does not feel like her relationship is on par with those of her Facebook friends. As Neira and Barber mention (2014), Facebook allows individuals to post only the best parts of their lives and when friends see these posts, they might think that their friends' lives are more exciting and overall better than their life. This line of thinking might also induce jealousy, which could then increase surveillance, helping to explain the positive relationship between general Facebook use and Facebook use for surveillance. While Facebook studies might not typically focus on how Facebook use plays into real world expectations about relationships, previous research regarding television viewing has shown that certain genres, such as romcoms and soap operas, are related to idealistic expectations and marital intentions (Segrin \& Nabi, 2002). It is entirely possible that some of these same expectations could be fostered by viewing friends' carefully moderated, and sometimes edited, Facebook profiles.

\section{Attachment}

Attachment and relational uncertainty. In line with existing research, both attachment-related anxiety and avoidance were negatively related to relational certainty; the more uncertain an individual was, the higher his or her level of either anxiety or avoidance in the current relationship. Individuals who exhibit signs of insecure attachment have trouble communicating under situations of uncertainty (Jang et al., 2007). Those high in the avoidant dimension tend to avoid problems and individuals high in the anxious dimension often focus on the negative and worry their partner will leave 
them (Mikulincer \& Shaver, 2003). As levels of anxiety or avoidance increase, these insecure behaviors occur and uncertainty increases.

Attachment and Facebook for IES. Past experiences in relationships are used to interpret the actions of current and future relationships. Secure individuals tend to have lower levels of uncertainty within their relationships and more satisfaction (Holland et al., 2011). Displaying a relationship status on Facebook was linked to higher levels of certainty, and lower levels of anxiety and avoidance. Because preoccupied and fearful individuals tend to be high in anxiety and might have trouble communicating with their partner in times of uncertainty, it was assumed that they would refer to Facebook in order to reduce uncertainty by surveying their partner. As mentioned, Facebook surveillance was not related to relational certainty, so while those who were high in the anxiety dimension did use Facebook for surveillance, this surveillance did not reduce or increase uncertainty. In an attempt to establish concrete meaning from an ambiguous event, those high in anxiety might employ passive strategies on their partner's Facebook, explaining why higher anxiety is related to higher surveillance. However, the information they are encountering might not do much to impact uncertainty in a positive or negative way. For this reason, the surveillance would not have an impact on relational certainty. However, although their relational certainty was not impacted by using Facebook for surveillance, the fact that individuals who are high in attachment anxiety report using Facebook for IES and those who are high in avoidance do not reinforces the overall idea of this study that different people use Facebook for different reasons.

Attachment-related anxiety was associated with Facebook for IES, however attachment-related avoidance was not. This is likely because more avoidant individuals 
typically avoid conflict and opening up to people. By using Facebook to survey their partner, they would have to acknowledge a conflict and a problem with the relationship and potentially communicate about that problem if they were not satisfied with the information that passive browsing afforded them. This stark contrast shows that attachment is related to Facebook use to some degree. Those who are more anxious used the site differently in at least one aspect (surveillance) than individuals who were more avoidant. If use was different for this aspect, it might be different in other areas as well.

\section{Self-Esteem}

Self-esteem and Facebook. Facebook use has had mixed results when it comes to self-esteem. Facebook has been found to increase social capital in users by allowing them access to broader networks and more social ties (Ellison et al., 2007). However, using a different measurement tool that outlined specific activities performed on Facebook in a later study, Kross and colleagues (2013) found a negative association with Facebook and social networking site use and self-esteem. The current study expected to find a negative relationship between Facebook use for IES and self-esteem, such that as individuals reported more surveillance use, they would also report less self-esteem. Previously used Facebook scales measure amount of time spent on Facebook or activities within Facebook, such as tagging pictures or adding friends, but not necessarily a goal minded activity such as surveillance. Using Facebook for surveillance to mitigate threats to a relationship might have a different relationship on self-esteem than untagging pictures or adding friends. Although there was no significant relationship between Facebook use for IES and relational uncertainty, when looking at the sample as a whole, a significant, correlation was found for Facebook surveillance and self-esteem. This is in line with the 
more recent research that cites a negative relationship between Facebook use and selfesteem. Perhaps surveillance is a behavior that is engaged in by individuals lower in selfesteem. Their line of thinking might be that checking in on their partner on Facebook will help them feel better about their relationship and in turn, seeing that they have been tagged in a status or picture by their partner, might make them feel better about themselves. This could be especially true for individuals with high attachment-related anxiety, who typically have lower self-esteem and consider themselves not worthy of love. The self-esteem of these individuals might decrease further by not seeing any posts that reinforce the positive aspects of their relationship. Because causation cannot be determined, it is impossible to know if those with lower self-esteem migrated towards Facebook in this study or if Facebook use resulted in lower self-esteem.

Attachment and self-esteem. Although this study did not include a hypothesis solely dedicated to the relationship between attachment anxiety and avoidance and selfesteem, tests were run to determine if the relationships would be similar to previous research indicating negative relationships. Indeed, a negative relationship was found for both anxiety and avoidance compared to self-esteem. Individuals with attachment-related anxiety generally have a warped self-concept and do not believe they are worth of love or that they are unlovable (Wu, 2009), so it makes since that anxious attachment dimensions were related to lower self-esteem.

Attachment as a moderator between Facebook for IES and self-esteem. While both dimensions of attachment, anxiety and avoidance, were negatively related to selfesteem and Facebook for surveillance was also negatively related to self-esteem, attachment did not act as a moderator for the relationship that existed between Facebook 
surveillance and self-esteem. It appears that neither attachment-related anxiety nor avoidance significantly changes the relationship between Facebook use for surveillance and self-esteem. Perhaps instead surveillance is used in an attempt to enhance selfesteem, which is part of the self-model associated with high attachment anxiety.

\section{Limitations and Future Research}

The first limitation of this study was the sample. While the population as a whole surpassed the 257 participants needed to gain power, current relationships were the main focus, and only 163 people were part of this group. Having more participants in a current relationship would have given the questions related to relational uncertainty more power. Significant results were not found concerning relational uncertainty and displaying a relationship on Facebook for those users who referred to previous relationships. A larger number of participants in this group might have led to different results. Nevertheless, it might be that people in current relationships are just more likely to display their relationship status than not. This should be addressed in future research. As this study suggested, displaying a relationship and linking profiles with a romantic partner were nearly always intertwined. Perhaps this is similar for being in a relationship and displaying it on Facebook such that as Facebook users enter a relationship, the norm is now to post that relationship on Facebook. In this study, displaying a relationship status and linking the status with a partner's profile were essentially one in the same. Research should look further into this to see if this relationship occurs in larger populations. If it does not, and more people display their status without actually linking it, research should look at whether a difference in relation certainty exists between just displaying a relationship status and displaying and linking a status. 
Participants for this study were also chosen based on a convenience method; the majority of them were from the communication department. While undergraduate college students are typical Facebook users, these specific undergraduates may have experience with a research methods course that discusses how to create similar surveys. This knowledge might have impacted how they approached the measurement instruments and how they answered the questions.

An additional limitation of this study was the survey measurement, which was based on self-report data. Data gathered in this manner is subject to inaccurate answers due to participants trying to get through the survey quickly as well as social desirability, or the likelihood that participants will answer questions in a way they think that others will favor. The survey instruments also asked participants to refer to their romantic relationships, which might have been a sensitive subject for some. Participants might not answer accurately either on purpose or because of denial, especially if they were uncertain of their current relationship.

While correlations were found to support the majority of the hypotheses for this study, these correlations did not indicate causation. Facebook use could be responsible for increasing uncertainty in romantic relationships for individuals that display their relationship status, but it could also be that individuals lower in relational certainty flock to the website. This is true of attachment anxiety as well: Facebook use for surveillance could be making users more anxious, or it could be that users who are anxious just use Facebook more for IES. Future research should try to discern causation from correlation.

Facebook is consistently one of the most visited websites in not only America, but also the world. Because of this, research needs to focus on how use can impact 
individuals in different areas of their life. Individual characteristics can influence how people use Facebook, as was evidenced by the fact that participants who were high in attachment anxiety were more likely to use Facebook for surveillance of their partner. Facebook use in general was also negatively related to relational certainty for those who displayed their status on the site. Because Facebook surveillance was not associated with relational uncertainty for any group, but time spent on Facebook was associated with uncertainty for those who displayed their relationship status on the site, future research should look into how Facebook use differs between these groups and other groups of people in general and why these findings differ. Is it strictly more time on the website that leads to less certainty, or the activities that are occurring during this time? Also, are personal characteristics more likely to drive certain people to use Facebook for things such as surveillance, or does more Facebook use incite these behaviors?

Attachment anxiety was related to both Facebook surveillance and relational uncertainty, but attachment avoidance was only associated with relational uncertainty and not surveillance. Future research could look into whether attachment moderates the relationship between Facebook surveillance and relational uncertainty. If enough participants in this study were high in attachment avoidance, this could have lowered the surveillance responses. Perhaps only surveying those high in anxiety would reveal a relation between Facebook surveillance and uncertainty. It is also unknown if attachment systems were activated for any of the participants in this study. Answers could have been different for an individual they had just been in an argument or fight with their partner or perhaps if their partner is not able to respond to all attachment behaviors because of their location (long distance relationship, military, etc.). If activated, it is possible that 
attachment-related anxiety and avoidance may have been more extreme. Individuals might be more likely to engage in surveillance behaviors, and admit to these behaviors, while their attachment system is activated which would make the data more accurate concerning attachment-related behaviors.

As far as Facebook and self-esteem are concerned, Facebook surveillance was negatively associated with self-esteem, but not with time on Facebook. Previous research in this area is conflicting, and these findings add to the conflict. Going forward, research needs to look into what activities are most common on Facebook and how those relate to self-esteem. People who spend an equal amount of time actively on Facebook might be doing completely different things. One person may participate in activities that impact self-esteem, but others may not. This suggests a strong need to go beyond the measurement of general time on Facebook, and instead into time performing specific activities.

\section{Conclusion}

This study adds to the ever increasing pool of knowledge about Facebook and its potential impacts on the lives of users. It successfully showed that Facebook use differs among users and has different implications for these users. Displaying a relationship status on Facebook was linked to increased relational certainty for participants in a current relationship; however, in this group of participants more time spent on Facebook was indicative of lower relational certainty. Similarly, participants with differing attachment behaviors were found to use the site for different activities and with different goals in mind. If individuals with differing approaches to romantic relationships differ in their use of the social networking site, what other personal characteristics create contrast 
in use and what are the potential benefits and drawbacks to this use? Only 10 individuals who attempted to partake in this study did not meet the requirement of having a Facebook account, and only 21 out of 261 participants were in a relationship with a partner who did not have a Facebook account. This shows how widely used Facebook is, and the fact that two thirds of individuals in a current relationship displayed their status on Facebook, and all but seven of them linked their profile with their partner indicates that norms are developing around Facebook for romantic relationships. As Facebook continues to be a staple in the social life of individuals, it is important to continue to research how it fits into the lives of users and what the potential implications are for using it. Although Facebook might not exist in the distant future, a new form of social networking or technology will likely take its place. Individual characteristics that exist offline spill over into the online world, and these sites might exacerbate these characteristics. Being in a romantic relationship in this day and age apparently means being in a relationship with Facebook as well, for better or worse, until uncertainty, do you part. 


\section{References}

Afifi, W. A. \& Burgoon, J. K. (1998). "We never talk about that": A comparison of cross-sex friendships and dating relationships on uncertainty and topic avoidance. Personal Relationships, 5, 255-272.

Afifi, W. A., \& Lucas, A. A. (2008). Information seeking in the initial stages of relational development. In S. Sprecher, A. Wenzel \& J. Harvey (Eds.), Handbook of relationship initiation.). New York, NY: Psychology Press.

Afifi, W. A., \& Reichert, T. (1996). Understanding the role of uncertainty in jealousy experience, expression, and expression. Communication Reports, 9, 93-103.

Ainsworth, M., \& Bowlby, J. (1991). An ethological approach to personality development. American Psychologist. 46, 333-341. Alexa top 500 global sites. (2013). Retrieved from http://www.alexa.com/topsites

Antheunis, M. L., Valkenburg, P. M., \& Peter, J. (2009). Getting acquainted through social network sites: Testing a model of online uncertainty reduction and social attraction. Computers in Human Behavior, 26, 100-109.

Antheuins, M. L., Schouten, A. P., Valkenburg, P. M., \& Peter, J. (2011). Interactive uncertainty reduction strategies and verbal affection in computer-mediated communication. Communication Research, 39, 757-779.

Bartholomew, K. (1990). Avoidance of intimacy: An attachment perspective. Journal of Social and Personal Relationships, 7, 147-178.

Bartholomew, K., \& Horowitz, L. M. (1991). Attachment styles among young adults: A test of a four-category model. Journal of Personality and Social Psychology, 61, 226-244.

Baxter, L. A., \& Wilmot, W. W. (1984). "Secret tests": Strategies for acquiring information about the state of the relationship. Human Communication Research, 11, 171-201.

Bell, R. A., \& Buerkel-Rothfuss, N. L. (1990). S(he) loves me, s(he) loves me not: Predictors of relational information-seeking in courtship and beyond. Communication Quarterly, 38, 64-82.

Berger, C. R. (1979). Beyond initial interaction: Uncertainty, understanding and the development of interpersonal relationships. In H. Giles \& R. N. St. Clair (Eds.), Language and Social Psychology. Oxford, UK: Basil Blackwell. 
Berger, C. R. (1987). Communicating under uncertainty. In M.E. Roloff \& G.R. Miller (Eds.) Interpersonal processes: New directions in communication research (pp. 39-62). Newbury Park, CA: Sage.

Berger, C. R., \& Bradac, J. J. (1982). Language and social knowledge: Uncertainty in interpersonal relationships. London: Edward Arnold.

Berger, C. R., \& Calabrese, R. J. (1975). Some explorations in initial inter-action and beyond: Toward a developmental theory of interpersonal communication. Human Communication Research, 1, 99-112.

Berkamn, L. F., Glass, T., Brissette, I., \& Seeman, T. E. (2000) From social integration to health: Durkheim in the new millennium. Social Science \& Medicine, 51, 843857.

Bowlby, J. (1969). Attachment and loss: Vol. 1. Attachment. New York: Basic Books.

Bowlby, J. (1973). Attachment and loss: Vol. 2. Separation. New York. Basic Books.

boyd, D. M., \& Ellison, N. B. (2008) Social network sites: Definition, history, and scholarship. Journal of Computer Mediated Communication, 13, 210-230.

boyd, d. (2008). Why youth (heart) social network sites: The role of networked publics in teenage social life. In D. Buckingham (Ed.), Youth, identity, and digital media Cambridge, MA: MIT Press.

Brashers, D. E. (2001). Communication and uncertainty management. Journal of Communication, 51, 477-497.

Brennan, K. A., Clark, C. L., \& Shaver, P. R. (1998). Self-report measurement of adult romantic attachment: An integrative overview. In J.A. Simpson \& W.S. Rholes (Eds.), Attachment theory and close relationships (pp. 46-76). New York: Guilford Press.

Bretherton, I. (1990). Communication patterns, internal working models and the intergenerational transmission of attachment relationships. Infant Mental Health Journal, 11, 237-252.

Bretherton, I. (1992). The origins of attachment theory: John Bowlby and Mary Ainsworth. Developmental Psychology, 28, 759-775

Bretherton, I., \& Munholland, K. (1999). Internal working models in attachment relationships: A construct revisited. In J. Cassidy and P. R. Shaver (Eds.), Handbook of attachment: Theory, research, and clinical applications (pp. 89114). New York: Guilford. 
Buunk, B. P. (1997). Personality, birth order, and attachment styles as related to various types of jealousy. Personality and Individual Differences, 23, 997 - 1006.

Byron, K., \& Baldridge, D. C. (2007). E-Mail recipients' impressions of senders' likability: The interactive effect of nonverbal cues and recipients' personality. Journal of Business Communication, 44, 137-160.

Cassidy, J. (1999). The nature of the child's ties. In J. Cassidy \& P. R. Shaver (Eds.), Handbook of attachment: Theory, research, and clinical implications (pp. 3 -20). New York: Guilford

Cassidy, J., \& Berlin, L. J. (1994). The insecure/ambivalent pattern of attachment: Theory and research. Child Development, 65, $971-981$.

Collins, N. L. (1996). Working models of attachment: Implications for explanation, emotion, and behavior. Journal of Personality and Social Psychology, 71, 810 832.

Collins, N. L., \& Read, S. J. (1990). Adult attachment, working models, and relationship quality in dating couples. Journal of Personality and Social Psychology, 58, $644-$ 663.

Deniz, M. E., Harmata, E., \& Ari, R. (2005). An investigation of social skills and loneliness levels of university students with respect to their attachment styles in a sample of Turkish students. Social Behavior and Personality, 33, 19-32.

DiTommaso, E., Brannen-McNulty, C., Ross, L., \& Burgess, M. (2003). Attachment styles, social skills, and loneliness in young adults. Personality and Individual Differences, 35, 303-312.

Dion, K. K., \& Dion, K. C. (1975). Self-esteem and romantic love. Journal of Personality, 43, 39-57.

Ellison, N. B., Steinfield, C., \& Lampe, C. (2007). The benefits of Facebook "friends": Social capital and college students' use of online social network sites. Journal of Computer-Mediated Communication, 12, 1143-1168.

Facebook (2013). Key facts. Retrieved September 29, 2013, from http://newsroom.fb.com/ImageLibrary/detail.aspx?MediaDetailsID1/44227

Facebook. Nd. Privacy settings and tools. Retrieved from https://www.facebook.com/settings/?tab=privacy\&privacy_source=settings_menu

Feeney, B. C., Cassidy, J., \& Ramose-Marcuse, F. (2008). The generalization of 
attachment representations to new social situations: Predicting behavior during initial interactions with strangers. Journal of Personality and Social Psychology, 95, 1481-1498.

Foster, J. D., Kernis, M. H., \& Goldman, B. M. (2007). Linking adult attachment to selfesteem stability. Self and Identity, 6, 64-73.

Fraley, R. C. (2010). A brief overview of adult attachment theory and research. Retrieved from http://internal.psychology.illinois.edu/ rcfraley/attachment.htm

Fox, J., Warber, K. M., \& Makstaller, D. C. (2013). The role of Facebook in romantic relationship development: An exploration of Knapp's relational stage model. Journal of Social and Personal Relationships, 1-24.

Gentile, B., Twenge, J. M., Freeman, E. C., \& Campbell, W. K. (2012). The effect of social networking websites on positive self-views: An experimental investigation. Computers in Human Behavior, 28, 1929-1933

Gibbs, J. L., Ellison, N. B., \& Lai, C. (2011). First comes love, then comes Google: An investigation of uncertainty reduction strategies and self-disclosure in online dating. Communication Research, 38, 70-100.

Goble, G. (2012, Sep 6). The history of social networking. Retrieved from http://www.digitaltrends.com/features/the-history-of-social-networking/

Guerrero, L. K. (1998). Attachment-style differences in the experience and expression of romantic jealousy. Personal Relationships, 5, $273-291$.

Hazan, C., \& Shaver, P. (1987). Romantic love conceptualized as an attachment process. Journal of Personality and Social Psychology, 52, 511 - 524.

Holland, A. S., Fraley, R. C., \& Roisman, G.I. (2012). Attachment styles in dating couples: Predicting relationship functioning over time. Personal Relationships, 19, 234-246.

Honeycutt, J. M., Cantrill, J. G., \& Greene, R. W. (1989). Memory structures for Relational escalation: A cognitive test of the sequencing of relational actions and stages. Human Communication Research, 16, 62-90.

Jang, S. A., Yoo, J. H., \& Tian, Y. (2007). Attachment, relational uncertainty, communication efficacy and avoidance following events that increase uncertainty in close relationships. Human Communication, 14, 205-219.

Jin, B., \& Peña, J. F. (2010). Mobile communication in romantic relationships: Mobile 
phone use, relational uncertainty, love, commitment, and attachment styles. Communication Reports, 23, 39-51.

Joinson, A. N. (2008). "Looking at," "looking up" or "keeping up with" people? Motives and uses of Facebook. In Proceedings of the 26th Annual SIGCHI Conference on Human Factors in Computing Systems (Florence, Italy, April 5-10 2008), CHI '08, ACM (pp. 1027 - 1036). New York: ACM Press.

Kalpidou, M., Costin, D., \& Morris, J. (2011). The relationship between Facebook and the well-being of undergraduate college students. CyberPsychology, Behavior, \& Social Networking, 14, 183-189.

Kinnunen, M., Feldt, T., Kinnunen, U., \& Pulkkinen, L. (2008). Self-esteem: An antecedent or a consequence of social support and psychosomatic symptoms? Cross-lagged associations in adulthood. Journal of Research in Personality, 42, 333-347.

Knobloch, L. K., \& Solomon, D. H. (1999). Measuring the sources and content of relational uncertainty. Communication Studies, 50, 261-278.

Knobloch, L. K., \& Solomon, D. H. (2005). Measuring conversational equality at the relational level. In V. Manusov (Ed.), The sourcebook of nonverbal measures: Going beyond words(pp. 295-307). Hillsdale, NJ: Lawrence Erlbaum.

Knobloch, L. K., Solomon, D. H., \& Cruz, M. G. (2001). The role of relationship development and attachment in the experience of romantic jealousy. Personal Relationships, 8, 205-225.

Kross, E., Verduyn, P., Demiralp, E., Park, J., Lee, D. S., Lin, N.,Shablack, H., Jonides, J., \& Ybarra, O. (2013). Facebook use predicts declines in subjective well-being in young adults. PLoS ONE 8(8): e69841. doi:10.1371/journal.pone.0069841

Lim, W. M. \& Ting, D., H. (2012) E-shopping: An analysis of the uses and gratifications theory. Modern Applied Science, 6, 48-63.

Marshall, T. C., Bejanyan, K., Castro, G., \& Lee, A. A. (2013) Attachment styles as predictors of Facebook related jealousy and surveillance in romantic relationships. Personal Relationships, 20,1-22.

Mathes, E. W., Adams, H. E., \& Davies, R. M. (1985). Jealousy: Loss of relationship rewards, Loss of self-esteem, depression, anxiety, and anger. Journal of Personality and Social Psychology, 48, 1552-1561.

Mickelson, K. D., Kessler, R. C., \& Shaver, P. R. (1997). Adult attachment in a nationally representative sample.Journal of Personality \& Social Psychology, 73, $1092-1106$. 
Mikulincer, M., \& Shaver, P. R. (2007).Attachment in adulthood: Structure, dynamics, and change. New York: Guilford.

Mikulincer, M., \& Shaver, P. R. (2003). The attachment behavioral system in adulthood: Activation, psycho-dynamics, and interpersonal processes. In M. P. Zanna (Ed.), Advances in experimental social psychology (pp. 53 - 152). San Diego, CA: Elsevier Academic.

Morey, J. N., Gentzler, A. L., Creasy, B., Oberhauser, A. N., Westerman, D. (2013). Young adults' use of communication technology within their romantic relationships and associations with attachment style. Computers in Human Behavior, 29, 1771-1778.

Muise, A, Christofides, E., \& Desmarais, S. (2009). More information than you ever wanted: Does Facebook bring out the green-eyed monster of jealousy? Cyber Psychology and Behavior, 12, 441-444.

Neira, C. J. B. \& Barber, B. L. (2014). Social networking site use: Linked to adolescents' social self-concept, self-esteem, and depressed mood. Australian Journal of Psychology, 66, 56-64.

Oldmeadow, J. A., Quinn, S., \& Kowert, R. (2013). Attachment style, social skills, and Facebook use amongst adults. Computers in Human Behavior, 29, 1142-1149.

Pfeiffer, S. M., \& Wong, P. T. P. (1989). Multidimensional jealousy. Journal of Social and Personal Relationships, 6, 181-196.

Planalp, S. (1987). Interplay between relational knowledge and events. In R. Burnett, P. McGhee, \& D. Clarke (Eds.), Accounting for relationships: Explanation, representation and knowledge (pp. 175-191). New York: Methuen.

Raacke, J. \& Bondes-Raacke, J. (2008). MySpace and Facebook: Applying the uses and gratifications theory to exploring friend-networking sites. CyberPsychology and Behavior, 11, 169-174.

Rosenberg, M. (1965). Society and the adolescent self-image. Princeton, NJ: Princeton University Press. Sharpsteen, D. J., \& Kirkpatrick, L. A. (1997). Romantic jealousy and adult romantic attachment. Journal of Personality and Social Psychology, 72, $627-640$.

Rubin, A. M. (1994). An examination of television viewing motives. Journal of Communication, 8, 141-165.

Segrin, C \& Nabi, R., L. (2002). Does television viewing cultivate unrealistic 
expectations about marriage? Journal of Communication, 52, 247-263.

Shoemaker, P. J. (1996). Hardwired for news: Using biological and cultural evolution to explain the surveillance function. Journal of Communication, 46, 32-47

Smith, E. R., Murphy, J., \& Coats, S. (1999). Attachment to groups: Theory and measurement. Journal of Personality and Social Psychology, 77, 94-110.

Stern, L. A., \& Taylor, K. (2007). Social networking on Facebook. Journal of the Communication, Speech \& Theatre Association of North Dakota, 20, 9-20.

Tazghini, S., \& Siedlecki, K. L. (2013). A mixed method approach to examining Facebook use and its relationship to self-esteem. Computers in Human Behavior, $29,827-832$.

Theiss, J. A. (2009). Relational uncertainty. In S. Littlejohn \& K. Foss (Eds.), Encyclopedia of communication (pp. 844-847). New York: Sage.

Thompson, R. A., (1999). Early attachment and later development. In J. Cassidy \& P.R. Shaver (Eds.), Handbook of attachment: Theory, research and clinical implications (pp. 265-286). New York: Guilford.

Tokunaga, R. S. (2011). Social networking site or social surveillance site? Understanding the use of inter-personal electronic surveillance in romantic relationships. Computers in Human Behavior, 27, 705 - 713.

Walther, J. B. (1996). Computer-mediated communication: Impersonal, interpersonal, and hyperpersonal interaction. Communication Research, 23, 3-43.

Watzlawick, P., Beavin, J. H., \& Jackson, D. D. (1967).Pragmatics of human communication. New York: Norton.

White, G. L., \& Mullen, P. E. (1989).Jealousy: Theory, research, and clinical strategies. New York: Guilford.

White, G. L. (1981). A model of romantic jealousy. Motivation and Emotion, 5, 295-310.

Wu, C. (2009). The relationship between attachment style and self-concept clarity: The mediation effect of self-esteem. Personality and Individual Difference, 47, 42-26 


\section{Appendices}

\section{Appendix A}

Recruitment Script

Thank you for participating in this study. The purpose of this study is to gauge social networking site use.

Participants in this study should be 18 years of age or older. Participation in this study is completely voluntary and your responses will remain confidential. You may quit at any time, and you may refuse to answer any questions on the survey. Choosing to participate or choosing to not participate will not negatively affect your course grade. If you choose to participate in this study, you will complete a questionnaire in exchange for extra credit in this course. The survey should take approximately 15 minutes.

There are only minimal risks associated with completing this survey. Overall, risks associated are less than one would experience in everyday life. By completing the survey, you are giving consent to participate in the study and you are certifying that you are 18 years of age or older.

When you complete the survey, please print the last page and fill out the information. Bring the completed page to the University Center Building 440 and drop it in the pink survey box to the left of the door by March 17th to be eligible for extra credit. YOU MAY ONLY TAKE THIS SURVEY FOR EXTRA CREDIT IN ONE CLASS. If you have the opportunity to complete this survey for extra credit in more than one course, or cannot complete this survey for any reason but still wish to receive credit, another extra credit opportunity similar in time and effort is available for you.

If you have questions or concerns about this study, or need an alternative extra credit opportunity, please contact Jenna Tucker at jetucker@pdx.edu.

At this point, if you choose to continue in this research study, please click " $>>$ " to continue to the survey.

Thank you very much for your participation. 


\section{Appendix B}

Informed Consent Form

You are invited to participate in a research study conducted by Jenna Tucker under the direction of Dr. Frank. This study attempts to collect information about your social networking site use, specifically Facebook. You were selected as a possible participant in this study because you are enrolled as an undergraduate in a communication course.

Procedures

If you decide to participate, you will be asked to complete the following questionnaire. The questionnaire will take approximately 15 minutes or less.

\section{Risks/Discomforts}

Risks are minimal for involvement in this study. However, you may feel uncomfortable when asked to share information about your relationship or Facebook use. You are welcome to skip any question that you feel uncomfortable answering.

\section{Benefits}

You may not receive any direct benefit from taking part in this study. However, it is hoped that through your participation, the study may help to increase knowledge which may help others in the future.

\section{Confidentiality}

All information that is obtained in connection with this study will be kept confidential and will only be reported in an aggregate format (by reporting only combined results and never reporting individual ones). All questionnaires will be concealed, and no one other than the research team will have access to them. At no point will you name be linked to your answers.

\section{Compensation}

You may earn academic extra credit for your participation. Follow the directions at the end of the survey to print and turn your survey completion form in to the pink "Survey Drop Box" to the left of the door on the book shelf in the Communication Department offices, UCB 441. Your form will not be linked to your survey responses. Your name is collected only so that your professor may give you extra credit for your class project.

Participation

Participation in this research study is completely voluntary. You have the right to 
withdraw at anytime or refuse to participate entirely, and it will not affect your course grade in the class or standing with the university. If you wish to receive extra credit but do not wish to complete the survey, contact the researcher for an alternative extra credit opportunity.

Questions about the Research

If you have questions or concerns regarding this study, contact Jenna Tucker jetucker@pdx.edu or Dr. Frank at 1frank@pdx.edu.

Questions about your Rights as Research Participants

If you have questions or concerns about your rights as a research subject, please contact The PSU Office of Research Integrity, $1600 \mathrm{SW} 4^{\text {th }}$ Ave., Market Center Building, Ste. 620, Portland, OR 97207; phone (503) 725-2227 or 1 (877) 480-4400. By completing this survey, you are certifying that you are 18 years of age or older, that you have read and understand the above information and agree to take part in the survey. Press the "Print" button below to keep a copy of this form for your own records. If at this point you choose to continue in this research study, please click ">>>" to continue. 


\section{Appendix C}

Survey

Do you have a Facebook account?
O Yes
O No

If No Is Selected, Then Skip To Thank you for participating!

Please answer the following questions about your current romantic relationship or most recent romantic relationship.

Is your relationship status listed on Facebook? (Currently or for your last relationship)
O Yes
O No

Is your relationship status with your partner displayed on Facebook so that your profiles are connected? (Example: Jane Doe is in a relationship with John Smith)
O Yes
O No

For this study, are you referring to a current relationship or a previous relationship you are no longer in?
Current relationship
Previous relationship 
Think about your current romantic relationship or your most recent romantic relationship. Please rate each statement on how certain you are concerning this relationship, where $1=$ completely uncertain and $6=$ completely certain.

\begin{tabular}{|c|c|c|c|c|c|c|}
\hline $\begin{array}{l}\text { Your } \\
\text { commitment } \\
\text { to the } \\
\text { relationship }\end{array}$ & 0 & 0 & 0 & 0 & 0 & 0 \\
\hline $\begin{array}{l}\text { Your } \\
\text { feelings } \\
\text { about the } \\
\text { relationship }\end{array}$ & 0 & 0 & 0 & 0 & 0 & 0 \\
\hline $\begin{array}{l}\text { How much } \\
\text { you are } \\
\text { romantically } \\
\text { interested in } \\
\text { your partner }\end{array}$ & 0 & 0 & 0 & 0 & 0 & 0 \\
\hline $\begin{array}{l}\text { Your view } \\
\text { of this } \\
\text { relationship }\end{array}$ & 0 & 0 & $\mathrm{O}$ & 0 & $\mathrm{O}$ & 0 \\
\hline $\begin{array}{l}\text { Whether or } \\
\text { not you } \\
\text { want this } \\
\text { relationship } \\
\text { to last }\end{array}$ & 0 & 0 & 0 & 0 & 0 & 0 \\
\hline $\begin{array}{l}\text { Your goals } \\
\text { for the } \\
\text { future of } \\
\text { this } \\
\text { relationship }\end{array}$ & 0 & 0 & 0 & 0 & 0 & 0 \\
\hline $\begin{array}{c}\text { Your } \\
\text { partner's } \\
\text { commitment } \\
\text { to this }\end{array}$ & 0 & 0 & 0 & 0 & 0 & 0 \\
\hline
\end{tabular}




\begin{tabular}{|c|c|c|c|c|c|c|}
\hline relationship & & & & & & \\
\hline $\begin{array}{l}\text { How your } \\
\text { partner feels } \\
\text { about the } \\
\text { relationship }\end{array}$ & $\mathrm{O}$ & 0 & $\mathrm{O}$ & 0 & 0 & 0 \\
\hline $\begin{array}{l}\text { How much } \\
\text { your partner } \\
\text { is } \\
\text { romantically } \\
\text { interested in } \\
\text { you }\end{array}$ & 0 & 0 & $\mathrm{O}$ & 0 & 0 & O \\
\hline $\begin{array}{c}\text { Your } \\
\text { partner's } \\
\text { view of this } \\
\text { relationship }\end{array}$ & 0 & 0 & $\mathrm{O}$ & 0 & $\mathrm{O}$ & 0 \\
\hline $\begin{array}{l}\text { Whether or } \\
\text { not your } \\
\text { partner } \\
\text { wants this } \\
\text { relationship } \\
\text { to last }\end{array}$ & 0 & 0 & 0 & 0 & 0 & 0 \\
\hline $\begin{array}{l}\text { Your } \\
\text { partner's } \\
\text { goals for the } \\
\text { future of } \\
\text { this } \\
\text { relationship }\end{array}$ & 0 & 0 & $\mathrm{O}$ & $\mathrm{O}$ & 0 & $\mathrm{O}$ \\
\hline $\begin{array}{l}\text { What you } \\
\text { can or } \\
\text { cannot say } \\
\text { to each } \\
\text { other in this } \\
\text { relationship }\end{array}$ & $\mathrm{O}$ & $\mathrm{O}$ & 0 & 0 & 0 & 0 \\
\hline $\begin{array}{l}\text { The norms } \\
\text { for this } \\
\text { relationship }\end{array}$ & 0 & 0 & 0 & 0 & 0 & 0 \\
\hline Whether or & 0 & 0 & 0 & 0 & 0 & 0 \\
\hline
\end{tabular}




\begin{tabular}{|c|c|c|c|c|c|c|}
\hline $\begin{array}{c}\text { not you and } \\
\text { your partner } \\
\text { feel the } \\
\text { same way } \\
\text { about each } \\
\text { other }\end{array}$ & & & & & & \\
\hline $\begin{array}{c}\text { The current } \\
\text { status of } \\
\text { this } \\
\text { relationship }\end{array}$ & 0 & 0 & 0 & 0 & 0 & 0 \\
\hline $\begin{array}{l}\text { The } \\
\text { definition of } \\
\text { this } \\
\text { relationship }\end{array}$ & 0 & 0 & 0 & 0 & 0 & 0 \\
\hline $\begin{array}{c}\text { How you } \\
\text { and your } \\
\text { partner } \\
\text { would } \\
\text { describe this } \\
\text { relationship }\end{array}$ & 0 & 0 & 0 & 0 & 0 & 0 \\
\hline
\end{tabular}

\begin{tabular}{|c|c|c|c|c|c|c|}
\hline $\begin{array}{c}\text { Whether or } \\
\text { not you and } \\
\text { your partner } \\
\text { will stay } \\
\text { together }\end{array}$ & 0 & 0 & 0 & 0 & 0 & 0 \\
$\begin{array}{c}\text { The future } \\
\text { of this } \\
\text { relationship }\end{array}$ & 0 & 0 & 0 & 0 & 0 & 0 \\
\hline
\end{tabular}

Please indicate your agreement with each of the following statements concerning your current relationship, where $1=$ strongly disagree and $7=$ strongly agree. If you are not currently in a relationship please refer to your most recent relationship.

\begin{tabular}{|l|l|l|l|l|l|l|l|}
\hline $\begin{array}{c}\text { I'm afraid } \\
\text { that I will }\end{array}$ & 0 & 0 & 0 & 0 & 0 & 0 & 0 \\
\hline
\end{tabular}




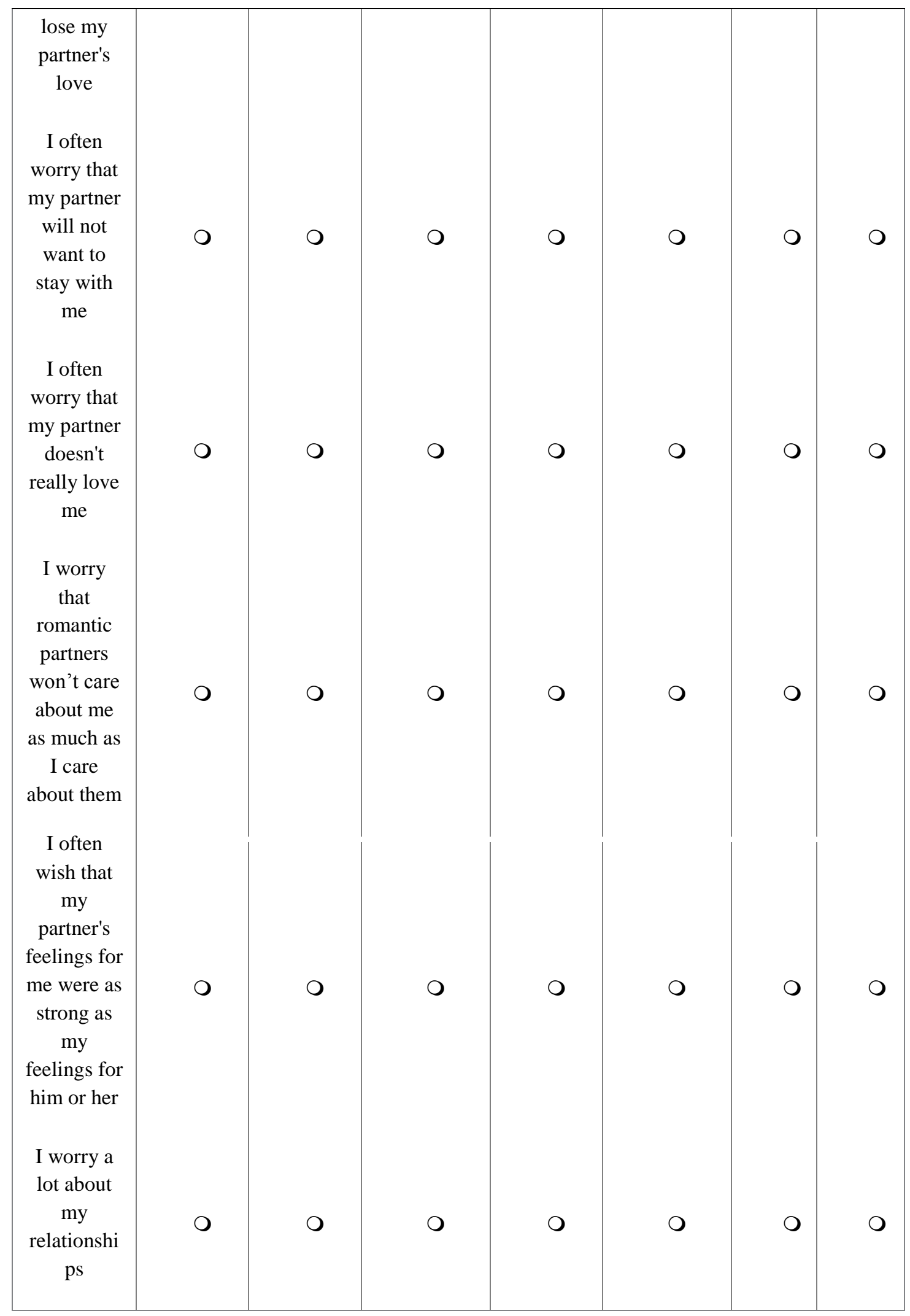




\begin{tabular}{|c|c|c|c|c|c|c|c|}
\hline $\begin{array}{l}\text { When my } \\
\text { partner is } \\
\text { out of } \\
\text { sight, I } \\
\text { worry that } \\
\text { he or she } \\
\text { might } \\
\text { become } \\
\text { interested } \\
\text { in someone } \\
\text { else }\end{array}$ & 0 & 0 & 0 & 0 & 0 & 0 & 0 \\
\hline
\end{tabular}

\begin{tabular}{|c|c|c|c|c|c|c|c|}
\hline $\begin{array}{c}\text { When I } \\
\text { show my } \\
\text { feelings for } \\
\text { romantic } \\
\text { partners, } \\
\text { I'm afraid } \\
\text { they will } \\
\text { not feel the } \\
\text { same about } \\
\text { me }\end{array}$ & $\mathrm{O}$ & 0 & 0 & 0 & 0 & 0 & 0 \\
\hline $\begin{array}{c}\text { I rarely } \\
\text { worry } \\
\text { about my } \\
\text { partner } \\
\text { leaving me }\end{array}$ & 0 & 0 & 0 & 0 & 0 & 0 & 0 \\
\hline $\begin{array}{c}\text { My } \\
\text { romantic } \\
\text { partner } \\
\text { makes me } \\
\text { doubt } \\
\text { myself }\end{array}$ & $\mathrm{O}$ & 0 & 0 & 0 & 0 & 0 & 0 \\
\hline $\begin{array}{l}\text { I do not } \\
\text { often }\end{array}$ & 0 & 0 & 0 & 0 & 0 & 0 & 0 \\
\hline
\end{tabular}




\begin{tabular}{|c|c|c|c|c|c|c|c|}
\hline $\begin{array}{c}\text { worry } \\
\text { about } \\
\text { being } \\
\text { abandoned }\end{array}$ & & & & & & & \\
\hline $\begin{array}{l}\text { I find that } \\
\text { my } \\
\text { partner(s) } \\
\text { don't want } \\
\text { to get as } \\
\text { close as I } \\
\text { would like }\end{array}$ & 0 & 0 & 0 & 0 & 0 & 0 & 0 \\
\hline
\end{tabular}

\begin{tabular}{|c|c|c|c|c|c|c|c|}
\hline $\begin{array}{c}\text { Sometimes } \\
\text { romantic } \\
\text { partners } \\
\text { change } \\
\text { their } \\
\text { feelings } \\
\text { about me } \\
\text { for no } \\
\text { apparent } \\
\text { reason }\end{array}$ & $\mathrm{O}$ & 0 & 0 & 0 & 0 & 0 & 0 \\
\hline $\begin{array}{l}\text { My desire } \\
\text { to be very } \\
\text { close } \\
\text { sometimes } \\
\text { scares } \\
\text { people } \\
\text { away }\end{array}$ & $\mathrm{O}$ & 0 & $\mathrm{O}$ & 0 & 0 & 0 & 0 \\
\hline $\begin{array}{l}\text { I'm afraid } \\
\text { that once a } \\
\text { romantic } \\
\text { partner } \\
\text { gets to } \\
\text { know me, } \\
\text { he or she } \\
\text { won't like }\end{array}$ & 0 & 0 & $\mathrm{O}$ & 0 & 0 & 0 & 0 \\
\hline
\end{tabular}




\begin{tabular}{|c|c|c|c|c|c|c|c|}
\hline $\begin{array}{c}\text { who I } \\
\text { really am }\end{array}$ & & & & & & & \\
\hline $\begin{array}{l}\text { It makes } \\
\text { me mad } \\
\text { that I don't } \\
\text { get the } \\
\text { affection } \\
\text { and } \\
\text { support I } \\
\text { need from } \\
\text { my partner }\end{array}$ & 0 & 0 & 0 & 0 & 0 & 0 & 0 \\
\hline $\begin{array}{l}\text { I worry } \\
\text { that I won't } \\
\text { measure up } \\
\text { to other }\end{array}$ & 0 & 0 & 0 & 0 & 0 & 0 & $\mathrm{O}$ \\
\hline $\begin{array}{l}\text { My partner } \\
\text { only seems } \\
\text { to notice } \\
\text { me when } \\
\text { I'm angry }\end{array}$ & 0 & 0 & 0 & 0 & 0 & 0 & 0 \\
\hline
\end{tabular}

Please indicate your agreement with each of the following statements concerning your current relationship, where $1=$ strongly disagree and $7=$ strongly agree. If you are not currently in a relationship please refer to your most recent relationship.

\begin{tabular}{|c|c|c|c|c|c|c|}
\hline $\begin{array}{c}\text { I prefer not to } \\
\text { show a } \\
\text { partner how I } \\
\text { feel deep } \\
\text { down }\end{array}$ & 0 & 0 & 0 & 0 & 0 & 0 \\
$\begin{array}{c}\text { I feel } \\
\text { comfortable } \\
\text { sharing my } \\
\text { private } \\
\text { thoughts and } \\
\text { feelings with } \\
\text { my partner }\end{array}$ & 0 & 0 & 0 & 0 & 0 & 0 \\
\hline
\end{tabular}




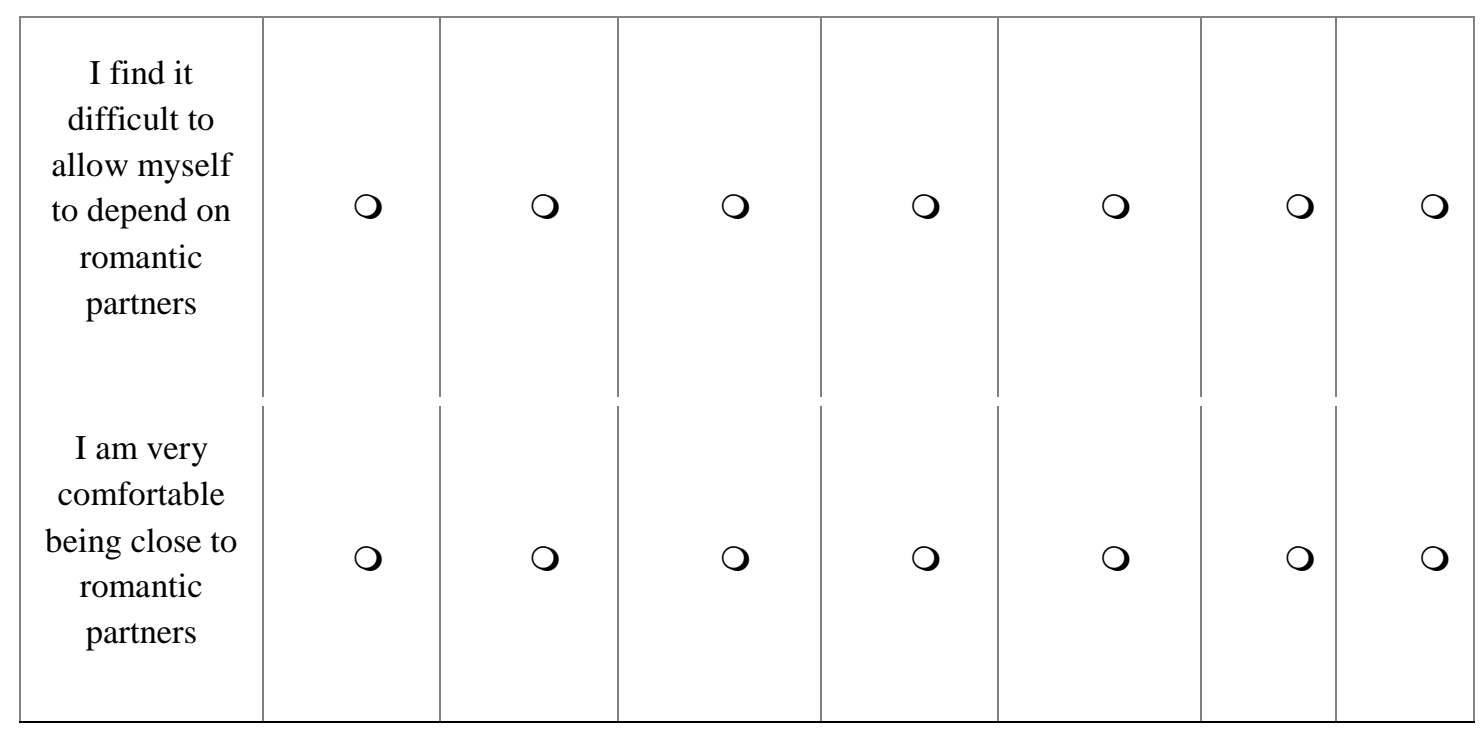

\begin{tabular}{|c|c|c|c|c|c|c|c|}
\hline $\begin{array}{l}\text { I don't feel } \\
\text { comfortable } \\
\text { opening up to } \\
\text { romantic } \\
\text { partners }\end{array}$ & 0 & 0 & 0 & 0 & 0 & 0 & 0 \\
\hline $\begin{array}{l}\text { I prefer not to } \\
\text { be too close to } \\
\text { romantic } \\
\text { partners }\end{array}$ & 0 & 0 & 0 & 0 & 0 & 0 & 0 \\
\hline $\begin{array}{c}\text { I get } \\
\text { uncomfortable } \\
\text { when a } \\
\text { romantic } \\
\text { partner wants } \\
\text { to be very } \\
\text { close }\end{array}$ & 0 & 0 & 0 & 0 & 0 & 0 & 0 \\
\hline $\begin{array}{l}\text { I find it } \\
\text { relatively easy } \\
\text { to get close to } \\
\text { my partner }\end{array}$ & 0 & 0 & 0 & 0 & 0 & 0 & 0 \\
\hline
\end{tabular}




\begin{tabular}{|c|c|c|c|c|c|c|c|}
\hline $\begin{array}{l}\text { It's not } \\
\text { difficult for } \\
\text { me to get } \\
\text { close to my } \\
\text { partner }\end{array}$ & 0 & 0 & 0 & 0 & 0 & 0 & 0 \\
\hline $\begin{array}{l}\text { I usually } \\
\text { discuss my } \\
\text { problems and } \\
\text { concerns with } \\
\text { my partner }\end{array}$ & 0 & 0 & 0 & 0 & 0 & 0 & 0 \\
\hline $\begin{array}{l}\text { It helps to } \\
\text { turn to my } \\
\text { romantic } \\
\text { partner in } \\
\text { times of need }\end{array}$ & 0 & 0 & 0 & 0 & 0 & 0 & 0 \\
\hline $\begin{array}{l}\text { I tell my } \\
\text { partner just } \\
\text { about } \\
\text { everything }\end{array}$ & O & 0 & 0 & 0 & 0 & 0 & 0 \\
\hline $\begin{array}{l}\text { I talk things } \\
\text { over with my } \\
\text { partner }\end{array}$ & 0 & 0 & 0 & 0 & 0 & 0 & 0 \\
\hline $\begin{array}{c}\text { I am nervous } \\
\text { when partners } \\
\text { get too close } \\
\text { to me }\end{array}$ & 0 & 0 & 0 & 0 & 0 & 0 & 0 \\
\hline $\begin{array}{c}\text { I feel } \\
\text { comfortable } \\
\text { depending on } \\
\text { romantic } \\
\text { partners }\end{array}$ & 0 & 0 & 0 & 0 & 0 & 0 & $c$ \\
\hline $\begin{array}{l}\text { I find it easy } \\
\text { to depend on } \\
\text { romantic } \\
\text { partners }\end{array}$ & 0 & 0 & 0 & 0 & 0 & 0 & 0 \\
\hline
\end{tabular}




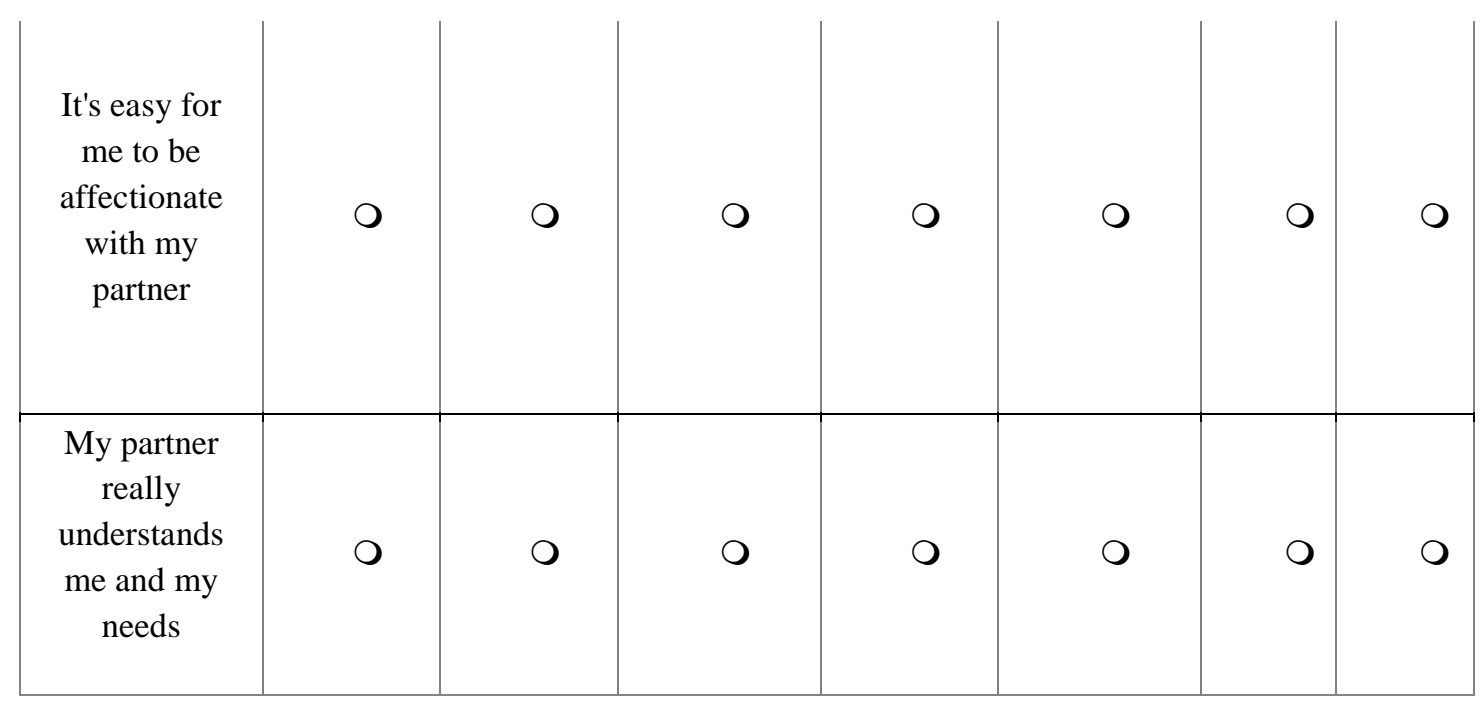

Please indicate your level of agreement with each of the following statements, where $1=$ strongly disagree and 4 = strongly agree.

\begin{tabular}{|c|c|c|c|c|}
\hline $\begin{array}{l}\text { I feel that I am } \\
\text { a person of } \\
\text { worth, at least } \\
\text { on an equal } \\
\text { plane with } \\
\text { others }\end{array}$ & 0 & 0 & 0 & 0 \\
\hline $\begin{array}{c}\text { I feel that I } \\
\text { have a number } \\
\text { of good } \\
\text { qualities }\end{array}$ & 0 & 0 & 0 & 0 \\
\hline $\begin{array}{l}\text { All in all, I am } \\
\text { inclined to feel } \\
\text { that I am a } \\
\text { failure }\end{array}$ & 0 & 0 & 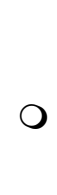 & 0 \\
\hline $\begin{array}{l}\text { I am able to do } \\
\text { things as well } \\
\text { as most people }\end{array}$ & 0 & 0 & 0 & 0 \\
\hline
\end{tabular}




\begin{tabular}{|c|c|c|c|c|}
\hline $\begin{array}{l}\text { I feel I do not } \\
\text { have much to } \\
\text { be proud of }\end{array}$ & 0 & 0 & 0 & 0 \\
\hline $\begin{array}{c}\text { I take a } \\
\text { positive } \\
\text { attitude toward } \\
\text { myself }\end{array}$ & 0 & 0 & 0 & 0 \\
\hline $\begin{array}{l}\text { On the whole, I } \\
\text { am satisfied } \\
\text { with myself }\end{array}$ & 0 & 0 & 0 & 0 \\
\hline $\begin{array}{l}\text { I wish I could } \\
\text { have more } \\
\text { respect for } \\
\text { myself }\end{array}$ & 0 & 0 & 0 & 0 \\
\hline $\begin{array}{l}\text { I certainly feel } \\
\text { useless at times }\end{array}$ & 0 & 0 & 0 & 0 \\
\hline $\begin{array}{l}\text { At times I think } \\
\text { that I am no } \\
\text { good at all }\end{array}$ & 0 & 0 & 0 & 0 \\
\hline
\end{tabular}

Please answer the following questions about your Facebook account.

In a typical week, how many days do you access your Facebook account?

On a typical day, about how many times do you check your Facebook account?

On a typical day, about how many minutes do you spend actively using Facebook? (Not just having it open in a browser)

The following is a list of statements pertaining to specific activities on Facebook. Please indicate your agreement with each of the following statements, where $1=$ strongly disagree and $7=$ strongly agree. 


\begin{tabular}{|c|c|c|c|c|c|c|c|}
\hline $\begin{array}{l}\text { I visit my } \\
\text { partner's } \\
\text { page often }\end{array}$ & 0 & 0 & 0 & 0 & 0 & $O$ & 0 \\
\hline $\begin{array}{c}\text { When } \\
\text { visiting my } \\
\text { partner's } \\
\text { Facebook } \\
\text { page, I read } \\
\text { the new } \\
\text { posts of } \\
\text { his/her } \\
\text { friends }\end{array}$ & 0 & 0 & 0 & O & 0 & 0 & 0 \\
\hline $\begin{array}{l}\text { I often } \\
\text { spend time } \\
\text { looking } \\
\text { through my } \\
\text { partner's } \\
\text { Facebook } \\
\text { pictures }\end{array}$ & 0 & 0 & 0 & $\mathrm{O}$ & 0 & $O$ & 0 \\
\hline $\begin{array}{c}\text { I pay } \\
\text { particularly } \\
\text { close } \\
\text { attention to } \\
\text { Facebook } \\
\text { news feeds } \\
\text { that concern } \\
\text { my partner }\end{array}$ & 0 & 0 & 0 & 0 & 0 & 0 & 0 \\
\hline
\end{tabular}




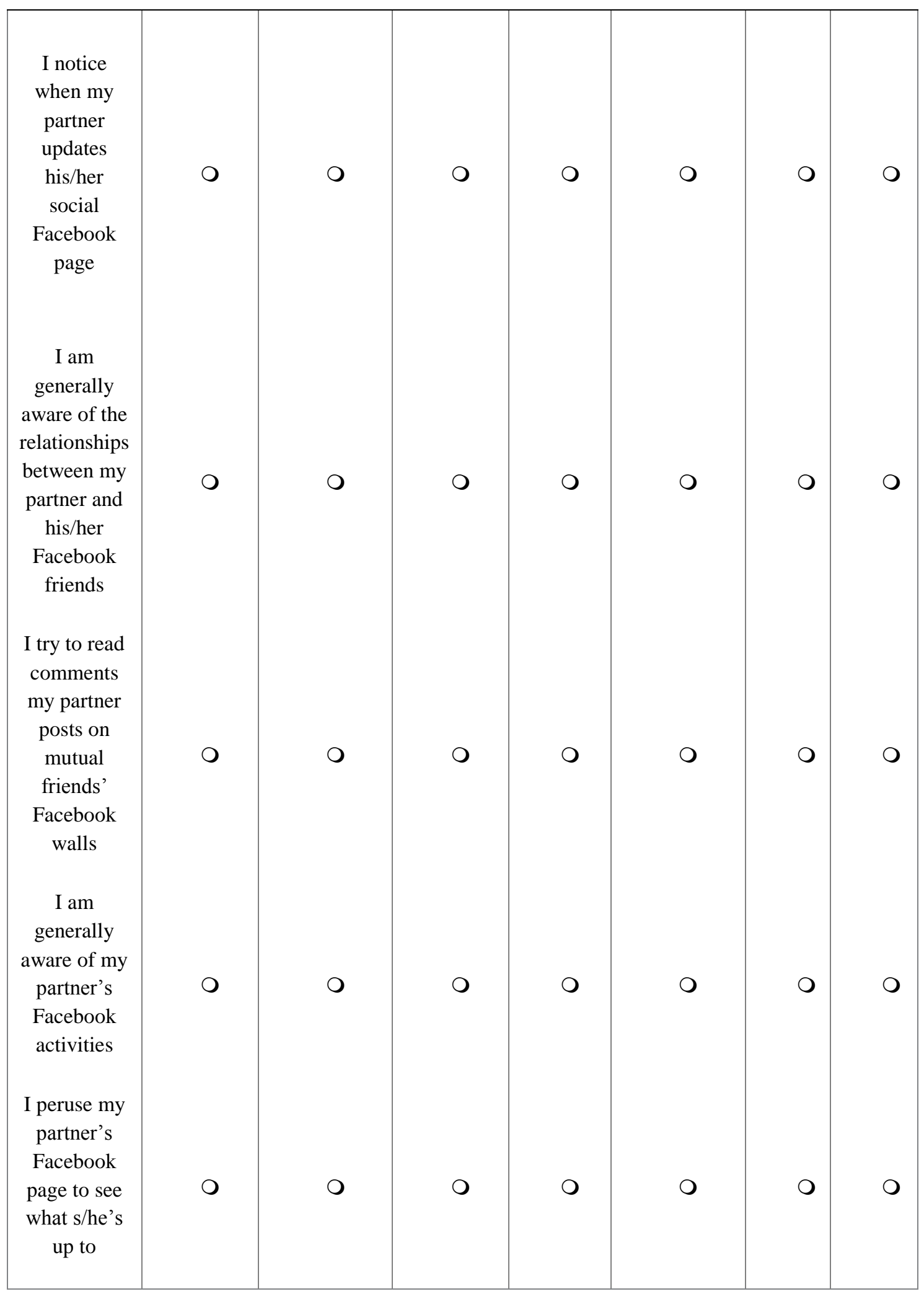




\begin{tabular}{|c|c|c|c|c|c|c|c|}
\hline $\begin{array}{c}\text { I know } \\
\text { when my } \\
\text { partner } \\
\text { hasn't } \\
\text { updated } \\
\text { his/her } \\
\text { Facebook } \\
\text { page in a } \\
\text { while }\end{array}$ & 0 & 0 & 0 & 0 & 0 & 0 & 0 \\
\hline $\begin{array}{c}\text { I try to } \\
\text { monitor my } \\
\text { partner's } \\
\text { behaviors } \\
\text { through } \\
\text { his/her } \\
\text { Facebook } \\
\text { page }\end{array}$ & 0 & 0 & 0 & 0 & 0 & $\mathrm{O}$ & 0 \\
\hline $\begin{array}{c}\text { I explore my } \\
\text { partner's } \\
\text { Facebook } \\
\text { page to see } \\
\text { if there is } \\
\text { anything } \\
\text { new or } \\
\text { exciting }\end{array}$ & 0 & 0 & 0 & 0 & 0 & 0 & 0 \\
\hline
\end{tabular}


Please indicate your agreement with each of the following statements concerning your relationship, where 1 $=$ Strongly Disagree and $7=$ Strongly Agree. (If you are not currently in a relationship please refer to your most important previous relationship.)

\begin{tabular}{|c|c|c|c|c|c|c|c|}
\hline $\begin{array}{l}\text { I prefer not to } \\
\text { show a partner } \\
\text { how I feel } \\
\text { deep down }\end{array}$ & 0 & 0 & 0 & 0 & 0 & 0 & 0 \\
\hline $\begin{array}{c}\text { I feel } \\
\text { comfortable } \\
\text { sharing my } \\
\text { private } \\
\text { thoughts and } \\
\text { feelings with } \\
\text { my partner }\end{array}$ & 0 & 0 & 0 & 0 & 0 & 0 & 0 \\
\hline $\begin{array}{c}\text { I find it } \\
\text { difficult to } \\
\text { allow myself } \\
\text { to depend on } \\
\text { my romantic } \\
\text { partner }\end{array}$ & 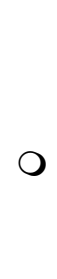 & 0 & 0 & 0 & 0 & 0 & $\mathrm{O}$ \\
\hline $\begin{array}{l}\text { I am very } \\
\text { comfortable } \\
\text { being close to } \\
\text { my romantic } \\
\text { partner }\end{array}$ & 0 & 0 & 0 & 0 & 0 & 0 & 0 \\
\hline $\begin{array}{l}\text { I don't feel } \\
\text { comfortable } \\
\text { opening up to } \\
\text { my romantic } \\
\text { partner }\end{array}$ & 0 & 0 & 0 & 0 & 0 & 0 & 0 \\
\hline
\end{tabular}

\begin{tabular}{|c|c|c|c|c|c|c|c|}
\hline $\begin{array}{c}\text { I prefer not to } \\
\text { be too close to } \\
\text { my romantic } \\
\text { partner }\end{array}$ & 0 & 0 & 0 & 0 & 0 & 0 & 0 \\
$\begin{array}{c}\text { I get } \\
\text { uncomfortable }\end{array}$ & 0 & 0 & 0 & 0 & 0 & 0 & 0 \\
\hline
\end{tabular}




\begin{tabular}{|c|c|c|c|c|c|c|c|}
\hline $\begin{array}{l}\text { when a } \\
\text { romantic } \\
\text { partner wants } \\
\text { to be very } \\
\text { close }\end{array}$ & & & & & & & \\
\hline $\begin{array}{l}\text { I find it } \\
\text { relatively easy } \\
\text { to get close to } \\
\text { my partner }\end{array}$ & 0 & 0 & 0 & 0 & 0 & 0 & 0 \\
\hline $\begin{array}{l}\text { It's not } \\
\text { difficult for } \\
\text { me to get } \\
\text { close to my } \\
\text { partner }\end{array}$ & 0 & 0 & 0 & 0 & 0 & 0 & 0 \\
\hline $\begin{array}{l}\text { I usually } \\
\text { discuss my } \\
\text { problems and } \\
\text { concerns with } \\
\text { my partner }\end{array}$ & 0 & 0 & 0 & 0 & 0 & 0 & 0 \\
\hline $\begin{array}{l}\text { It helps to turn } \\
\text { to my } \\
\text { romantic } \\
\text { partner in } \\
\text { times of need }\end{array}$ & 0 & 0 & 0 & 0 & 0 & 0 & 0 \\
\hline
\end{tabular}

\begin{tabular}{|c|c|c|c|c|c|c|c|}
\hline $\begin{array}{l}\text { I tell my } \\
\text { partner just } \\
\text { about } \\
\text { everything }\end{array}$ & $\mathrm{O}$ & 0 & 0 & 0 & 0 & O & O \\
\hline $\begin{array}{l}\text { I talk things } \\
\text { over with my } \\
\text { partner }\end{array}$ & $\mathrm{O}$ & 0 & 0 & 0 & 0 & $\mathrm{O}$ & $\mathrm{O}$ \\
\hline $\begin{array}{l}\text { I am nervous } \\
\text { when my } \\
\text { partner get too }\end{array}$ & 0 & 0 & 0 & 0 & 0 & O & 0 \\
\hline
\end{tabular}




\begin{tabular}{|c|c|c|c|c|c|c|c|}
\hline close to me & & & & & & & \\
\hline $\begin{array}{l}\text { I feel } \\
\text { comfortable } \\
\text { depending on } \\
\text { my romantic } \\
\text { partner }\end{array}$ & 0 & 0 & 0 & 0 & 0 & 0 & 0 \\
\hline $\begin{array}{l}\text { I find it easy } \\
\text { to depend on } \\
\text { my romantic } \\
\text { partner }\end{array}$ & 0 & 0 & 0 & 0 & 0 & 0 & 0 \\
\hline $\begin{array}{l}\text { It's easy for } \\
\text { me to be } \\
\text { affectionate } \\
\text { with my } \\
\text { partner }\end{array}$ & 0 & 0 & 0 & 0 & 0 & 0 & 0 \\
\hline $\begin{array}{l}\text { My partner } \\
\text { really } \\
\text { understands } \\
\text { me and my } \\
\text { needs }\end{array}$ & 0 & 0 & 0 & 0 & 0 & 0 & 0 \\
\hline
\end{tabular}


Next, I am going to ask you some more questions about yourself. Please answer to the best of your ability.

What gender do you identify with?

- Male

- Female

What is your current standing in school?
Freshman
O Sophomore
O Junior
O Senior
O Other

Answer If What is your academic status? Other Is Selected

You choose other for academic status. Please explain.

What year were you born?

What is your race?
O White/Caucasian
O African American
O Hispanic
O Asian
O Native American
O Pacific Islander
O Other

Thank you for participating! 